This article has been scanned by iThenticat No plagiarism detected

Volume 3, Issue 6, December 2021

p. 208-223

\title{
ATTITUDES OF GOVERNMENT SCHOOL PRINCIPALS TOWARDS INTEGRATING STUDENTS WITH PHYSICAL DISABILITIES IN NABLUS GOVERNORATE
}

http://dx.doi.org/10.47832/2757-5403.6-3.15

Rola Abd Al-Rahman ALKHARRAZ ${ }^{1}$ \& Majdi Hamad Tawfik AL-ATARI 2

\begin{abstract}
:
The study aimed to measure the attitudes of public school principals towards integrating students with motor disabilities in Nablus governorate and to measure the differences in the attitudes of government school principals towards integrating students with mobility disabilities in Nablus Governorate according to the different variables (gender, educational level, experience), and the descriptive survey method was used, and it was The study population consisted of all school principals in Nablus governorate, totaling (267) principals. The questionnaire was randomly distributed to a sample of (167) principals in Nablus governorate, which was statistically analyzed. The study showed the presence of high positive attitudes among public school principals towards integrating students with motor disabilities in Nablus governorate, and the presence of apparent differences in the attitudes of government school principals towards integrating students with motor disabilities in Nablus governorate due to gender in favor of females, and the absence of differences due to educational level and experience Based on the results of the study, it recommends preparing schools in a way that contributes to educating all workers to better accept the idea of inclusion in order to be successful in an optimal manner, and the need to issue legislation by the competent authorities, which guarantees the principle of equal opportunities for the disabled to obtain education, and the necessity of holding courses And workshops for managers in the field of inclusion of the disabled and special methods of dealing with them.
\end{abstract}

Key words: Attitudes, Public School Principals, İnclusion Of Students With Motor Disabilities.

\footnotetext{
${ }^{1}$ Researcher , Arab American University, Palestine, Rola nablus123@hotmail.com, https://orcid.org/00000003-0563-286X

${ }^{2}$ Researcher, Arab American University, Palestine
}

Copyright $(\mathcal{C}$ Published by IJHER Journal, www.ijherjournal.com Rimar Academy, Fatih, Istanbul, 34093 Turkey

All rights reserved 


\title{
اتجاهات مديري المدارس الحكومية نحو دمج الطلبة ذوي الإعاقة الحركية في محافظة نابلس
}

\author{
رولا عبد الرحمن محمد سعيد الخراز 3
}

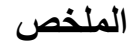

هدفت الدراسة لقياس اتجاهات مدراء المدارس الحكومية نحو دمج الطلاب ذوي الإعاقة

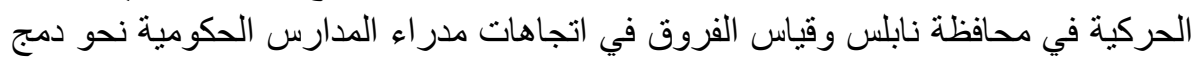
الطلاب ذوي الإعاقة الحركية في محافظة نابلس باختلاف المتغيرات (الجنس، المستوى الميات

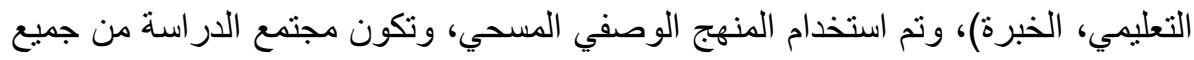
مديري المدارس الحكومية في محافظة نابلس والبالغ عددهم (267) مدير ومديرة، نمائمة اختيار منهم عينه عشوائية قوامها (167) مدير ومديرة، ونية ونم استخدام استبانه كأداة

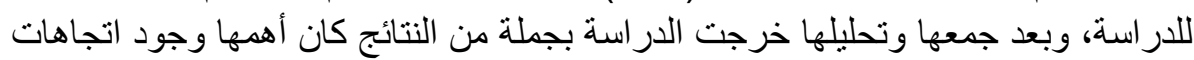

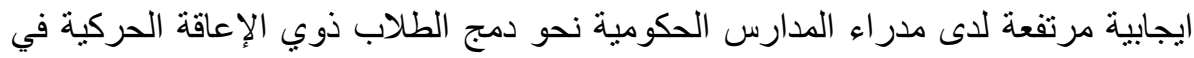

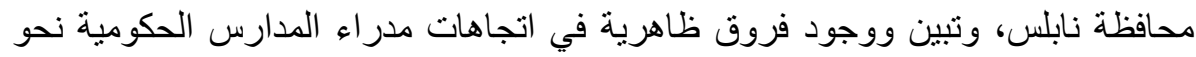

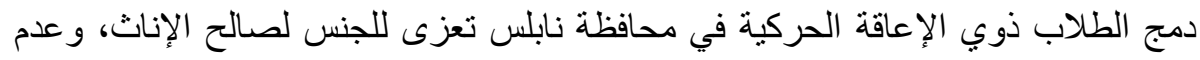

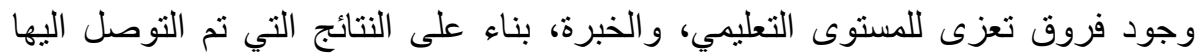

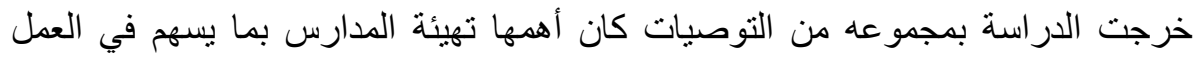

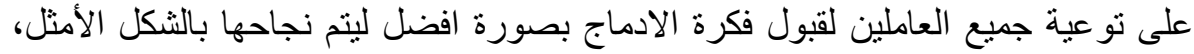

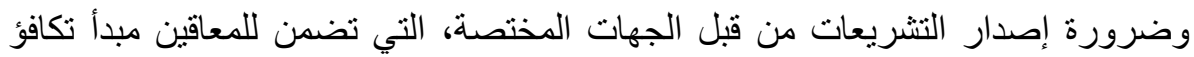

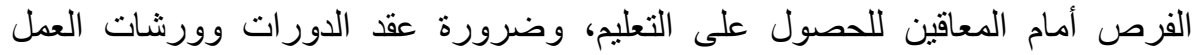

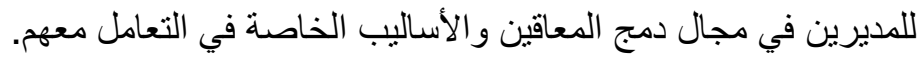

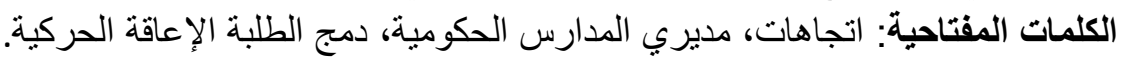

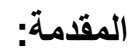

يعتبر مفهوم دمج الطلبة ذوي الإعاقة الحركية مفهوماً حديثاً وقد استخدم البعض مصطلح التكامل (Integration)

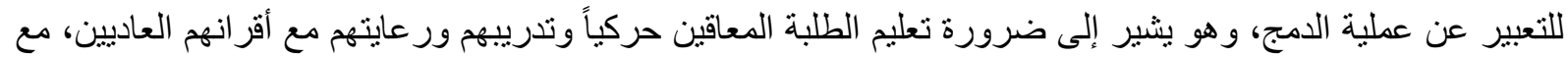

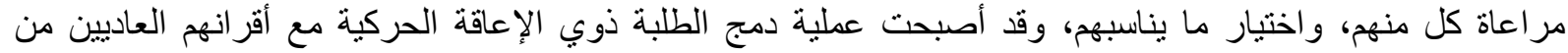
الموضوعات التي تستحوذ على اهتمام كبير في جميع دول العالم، حيث أن غالبية الدول تميل تدريجياً إلى تقديم الخدمات

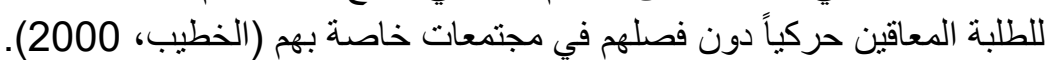
ولتحقيق جاهزية الدمج، فإن تأهيل المعلمين واشر اكهم في تنظيم عملية الدمج بتوفير الكفايات المهنية و التأهيل قبل الخدمة التهائ

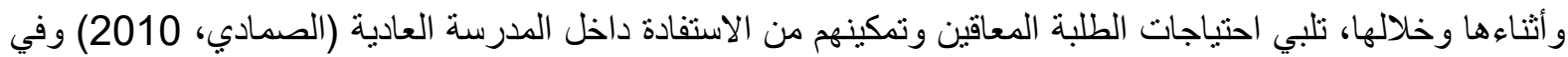

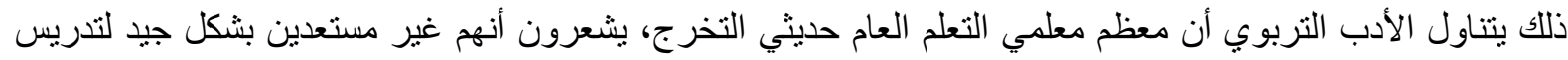
الطلبة المعاقين، حيث لا يقومون بإدارة سلوكيات الطلبة المعاقين المدمجين بشكل فعال (Futernick, 2007)؛

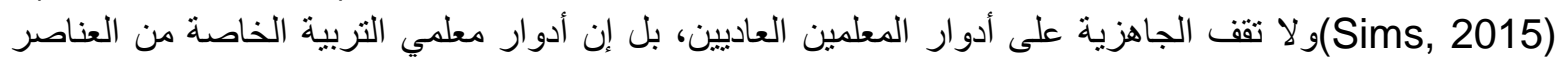

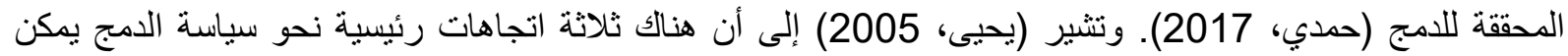
الإشارة إليها على النحو التالي: التحي،

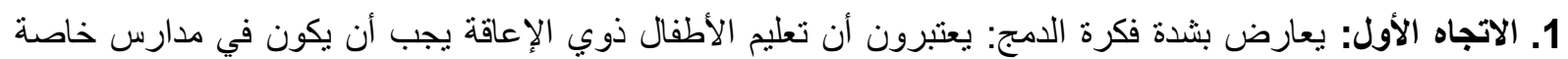

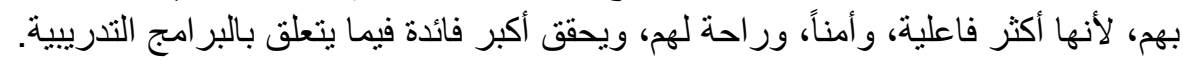


2. الاتجاه الثاني: يؤيد بثدة فكرة الدمج: يعتبرون أن الدمج له أثر في تعديل اتجاهات المجتمع والتخلص من عزل الأطفال الذين برأيهم يسببون عادة وصمة عجز وقصور، ومن الصفات السلبية التي قد يكون أثنر على الطفل ذانهاتهات

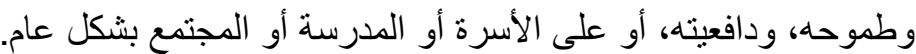

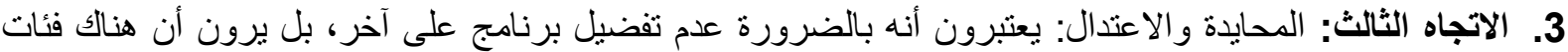
ليس من السهل دمجها بل يفضل تقديم الخدمات الخاصة بهاء الأن من خلال مؤسسات خاصة. ويمكن تلخيص ايجابيات الدمج بأنه يساعد أسر الأفراد ذوي الإعاقة من التخليص بالثعور بالذنب والاحباط، ويساعد في

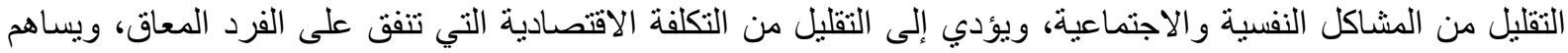

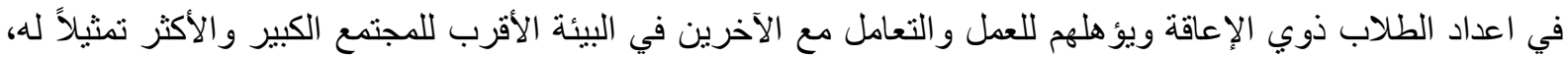

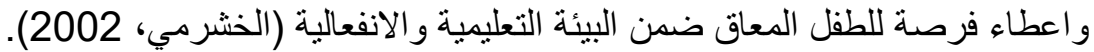

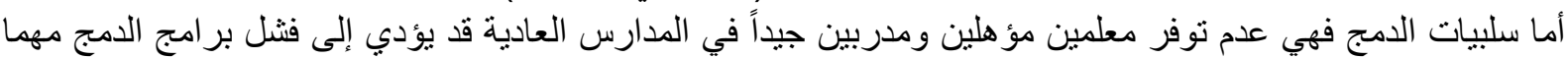

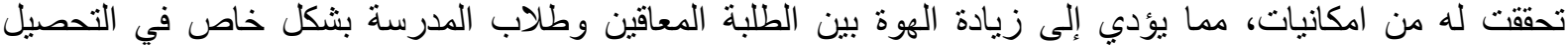

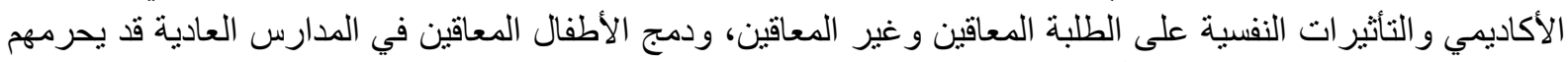

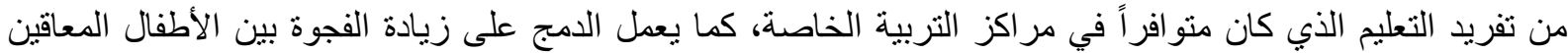

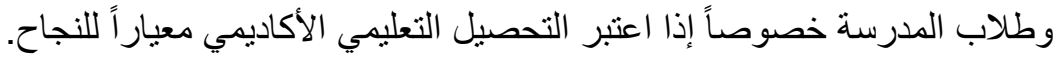

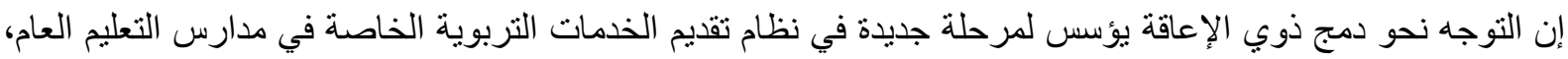
الأمر الذي أدى وسيؤدي إلى إحداث تغيرات في أنظمة المدارس العادية مما يزيد من الأعباء الوظيفية لمدراء هذاء هذاء

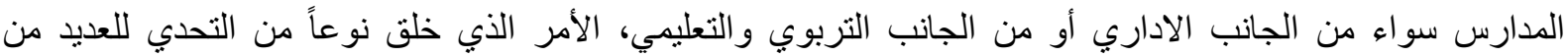

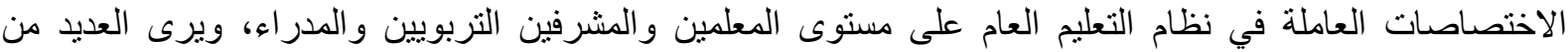
الباحثين بأن الددير هو العنصر الأساس ومفتاح النجاح لعملية الدمج (Hipp and Huffiman, 2000)

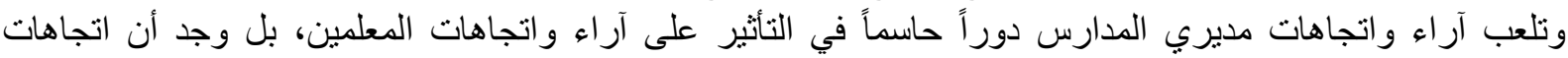
المديرين الايجابية هي العامل الأساسي في نجاح وتطبيق سياسة الدمج لكافة الفئات الخاصة (Irvine et al.,2010)

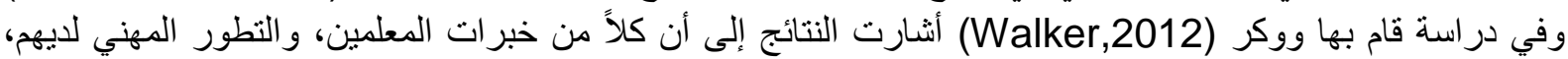

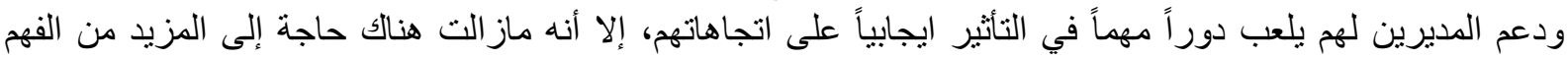

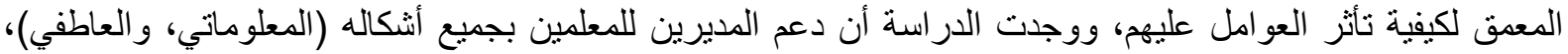

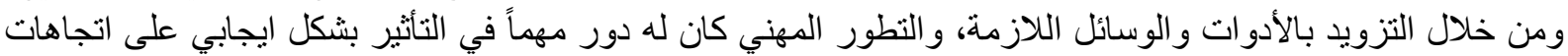
المعلمين. وتؤثر طبيعة الإعاقة ودرجتها في رغبة المعلمين في عمل التكيفات اللازمة، وثقتهم بأنفهم من حيث قدرتهم على إدارة الصف بفاعلية، والعديد من المعلمين يرون بأنهم غير قادرين على تدريس الطلبة ذوي الإحتياجات الخاصة في الصفوف

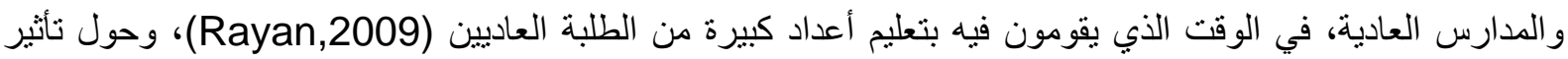

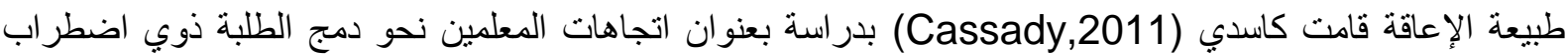
التوحد والاضطر ابات السلوكية والانفعالية، وبينت النتائج أن خصائص الأطفال في هاتين الفيتنين تؤثر في رغبة التئ المعلمين

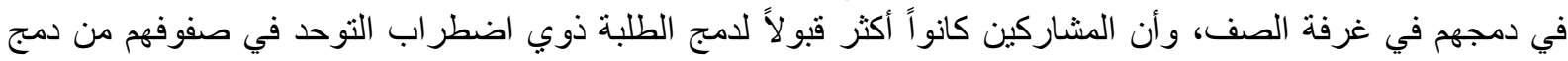
الطلبة ذوي الاضطر ابات السلوكية و الانفعالية. ودمج الأطفال المعاقين في المدارس العادية ينطوي على تحديات عديدة، ولإلية وقد تترتب عليه مشكلات متنو عتة، فالمعلمون

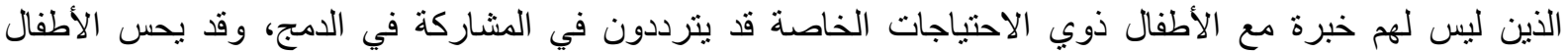

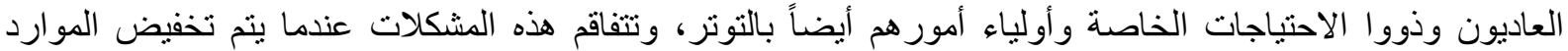

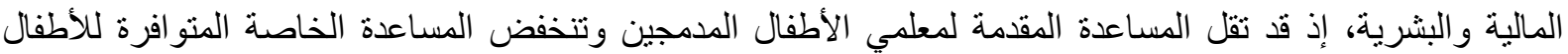

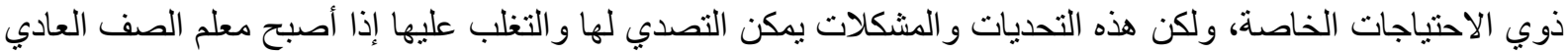

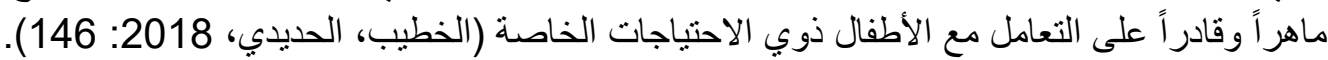
ويشكل الأفر اد ذوي الإعاقة في فلسطين ما نسبته (2.1\%) من مجمل السكان موزعون بنسبة (48\%) في الضفة الغربية

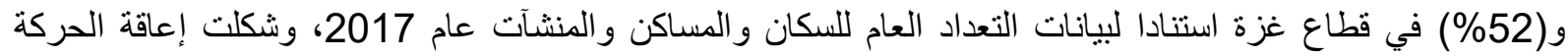
و استخدام الأيدي النسبة الأعلى من الإعاقات بين الأفراد ذوي الإعاقة حيث بلغ عدد الأفراد ذوي إعامات العاقة الحركة واستخدام

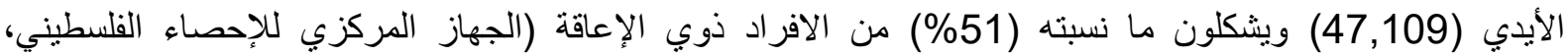


2019)، لذا جاءت الدراسة الحالية لتبحث في اتجاهات مديري المدارس الحكومية نحو دمج الطلبة ذوي الإعاقة الحركية في محافظة نابلس.

مشكلة الاراسة:

يلعب المديرون دوراً قيادياً وداعماً لا غنى عنه لإنجاح برامج الدمج الثامل، من خلال تذليل العقبات التي قد تحول دون

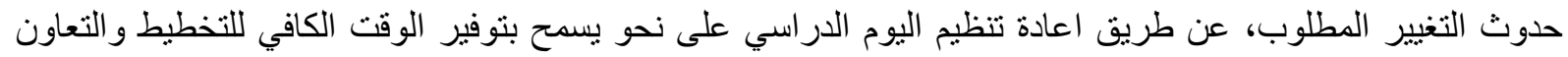

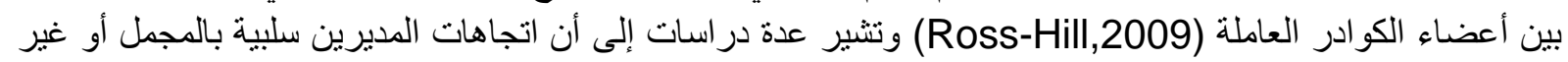

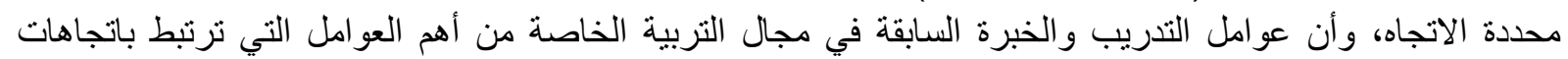

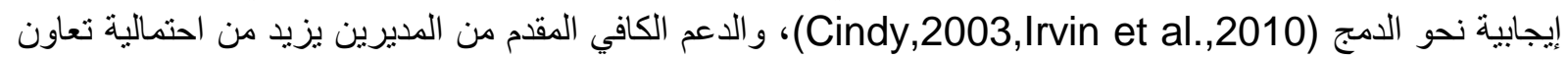

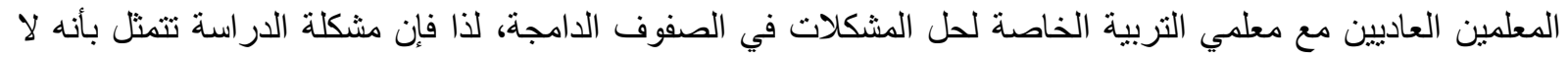

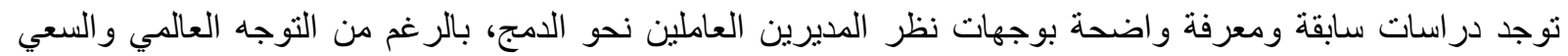

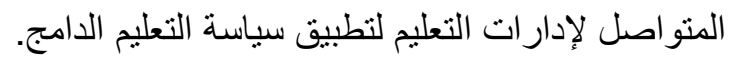

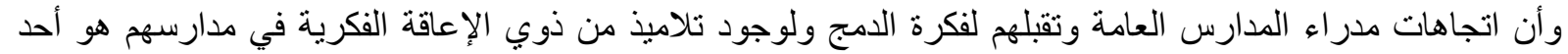

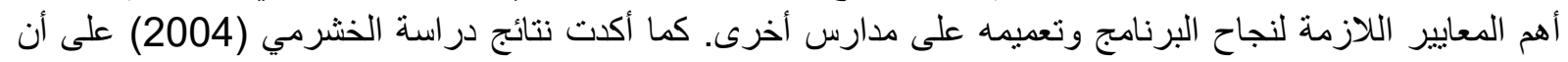

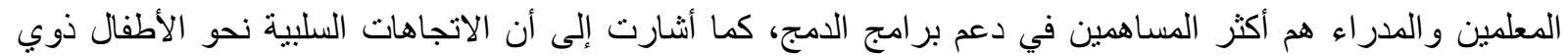

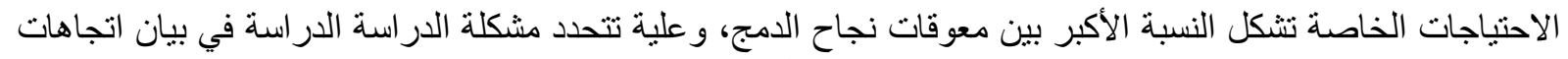

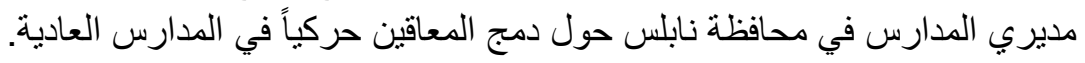

أسئلة الاراسة:

تسعى الدراسة إلى الإجابة عن التساؤلات التالية:

- ما اتجاهات مدر اء المدارس الحكومية نحو دمج الطلاب ذوي الإعاقة الحركية في محافظة نابلس؟

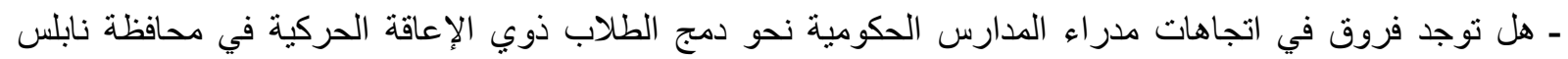
باختلاف المتغير ات (الجنس، المستوى التعليمي، الخبرة)؟

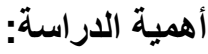

تأني أهمية الدراسة من أهمية فهم وجهات نظر المديرين في الددارس العادية الذين سيشرفون ويعلمون الطلبة ذوي

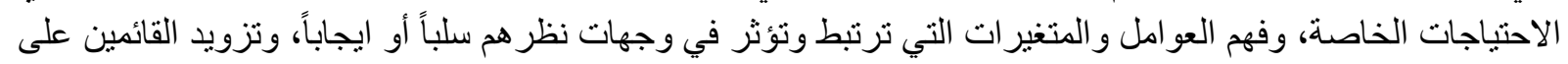

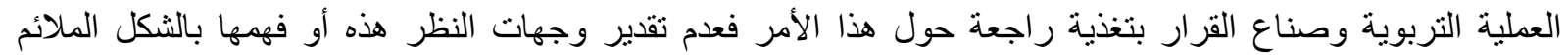

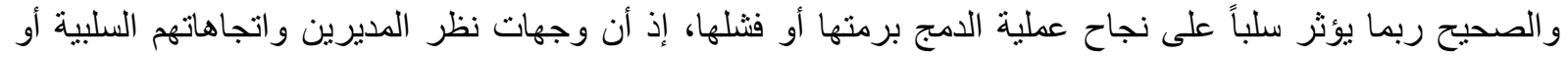

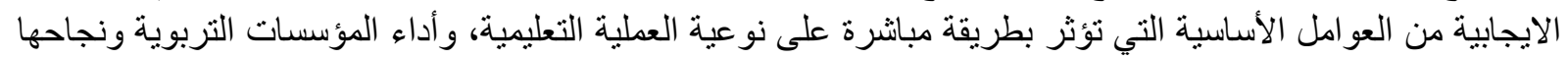

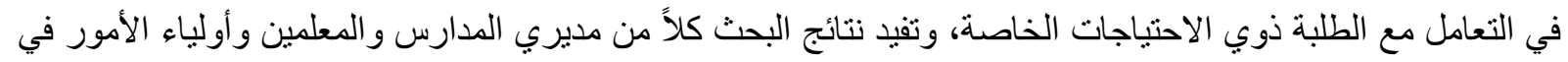

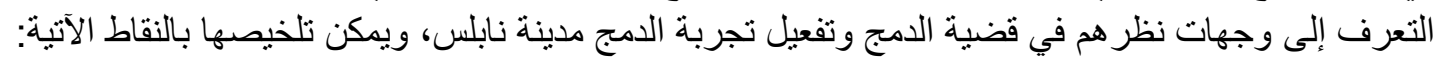
ـ تسهم نتائج البحث في توعية مديري المدارس والمعلمين وأولياء الأمور بأهمية دمج ذوي الحاجات الخاصة بمدارس التعليم الأساسي العادية.

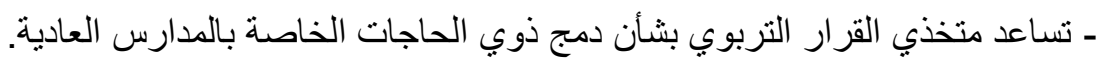

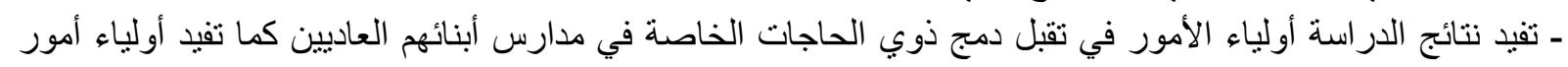

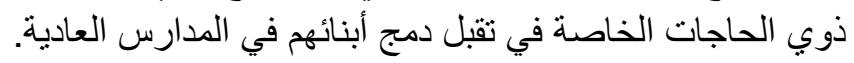
ـ توفير بيانات عن نتائج تجربة دمج ذوي الحاجات الخاصة لمخططي المناهج الدراسية و المسؤولين عن إدارة التعليم. 
ـ قياس اتجاهات مدر اء المدارس الحكومية نحو دمج الطلاب ذوي الإعاقة الحركية في محافظة نابلس.

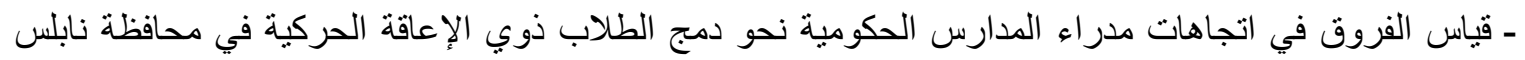
باختلاف المتغيرات (الجنس، المستوى التعليمي، الخبرة).

مصطلحات الاراسة:

الامج التعليمي أو التربوي: هو احداث نوع من التفاعل بين الأطفال ذوي الاحتياجات الخاصة مع الأطفال العاديين

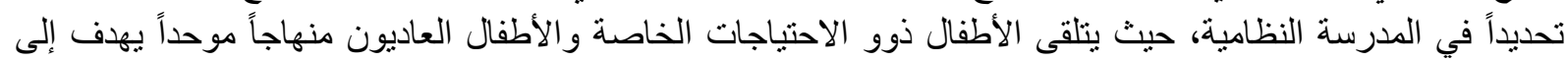
تعليم الطلاب ذوي الاحتياجات الخاصة الجزء الأكبر من بر امجهم الأكاديمية والاجتماعية في الفصول الإلفال العادية العادية (العزيز، . (2005

التعريف الاجرائي:

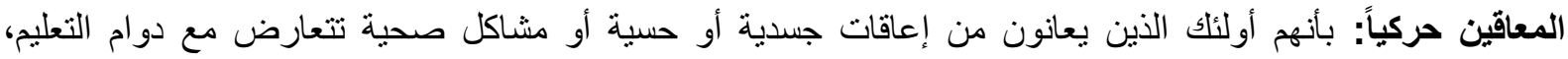
ولدرجة أنه ربما كانو الحاجة إلى خدمات تربوية وطبية ونفسية وتدريب وتجهيز ات ألى خاصة (عبيد، 2000)

التعريف الاجرائي

الإعاقة الحركية: حالة من نقص الكفاءة أو انخفاض مستوى الوظائف الحركية للأطر اف أو العظام أو العضلات أو النظام العصبي للجسم مما يؤدي إلى فقد القدرة على تحريك الجسم أو أحد أعضائه (الروسان, 2000).

التعريف الاجرائي

الاتجاهات: هي تقييمات أو مشاعر وجدانية أو استعدادات نفسية أو أفكار معرفية متعلمة يحملها الفرد وتتجسد على شكل

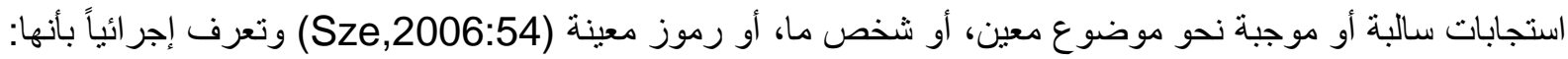

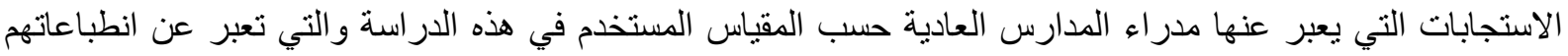
و أفكار هم حول دمج ذوي الإعابة الفئة الفكرية في المدارس العامة.

التعريف الاجرائي

مدراء المدارس: يعرف المدير بأنه الجهة المخولة بتنفيذ الخطط والبرامج، وفقاً لسياسات مرسومة، ومشففوعة باللوائح

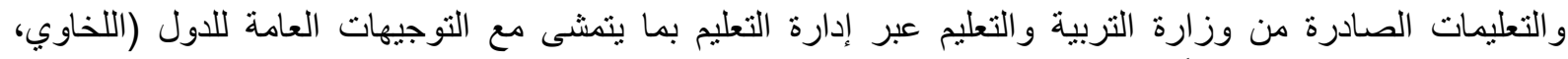

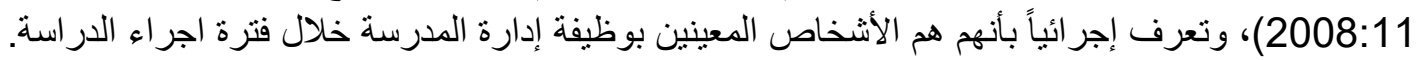

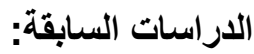

من أهم الدراسات ذات الصلة بموضوع الدراسة الحالية ما يلي:

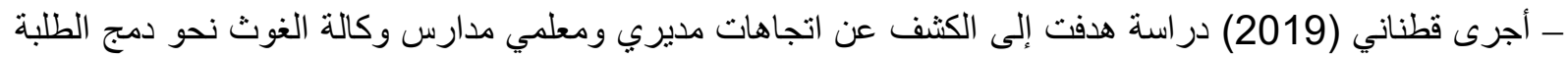

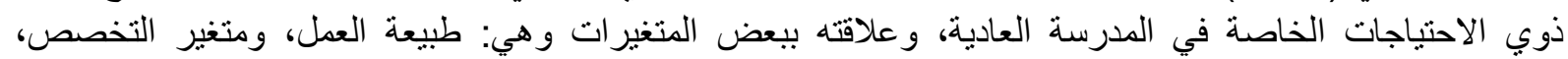

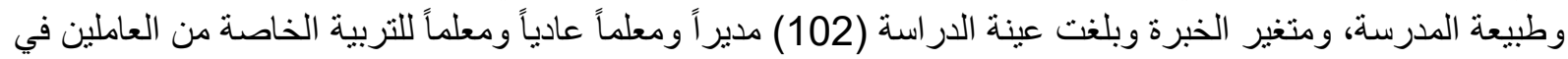

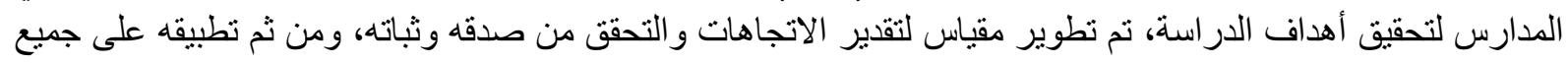

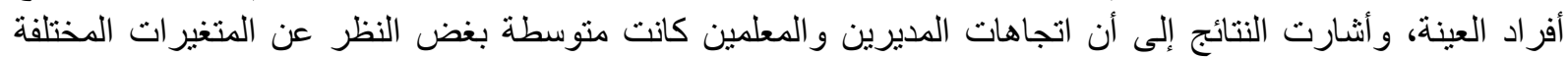

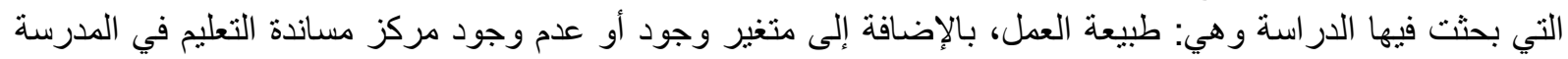

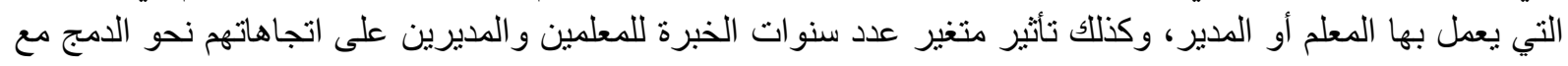
وجود فروق ذي دلالة في الاتجاهات بين المعلمين لصالح معلمي التربية الخاصة، إذ كانت اتجاهاتهم مرتفعة في حين كان

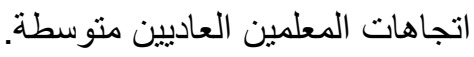


- و أجرى الحبيب (2018) دراسة هدفت للتعرف إلى اتجاهات الإداريين والمعلمين نحو دمج الطلبة الصم في المدارس

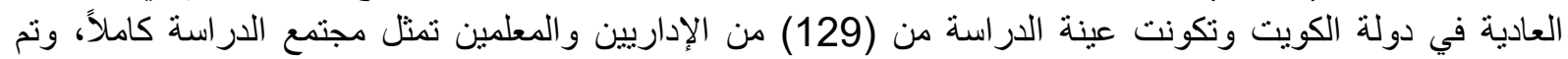

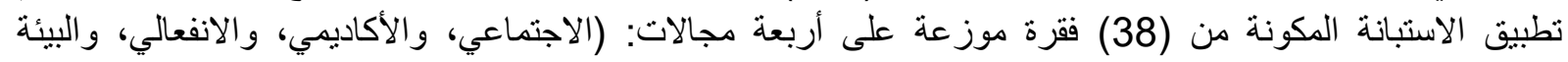

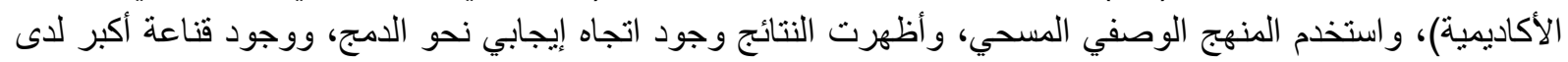

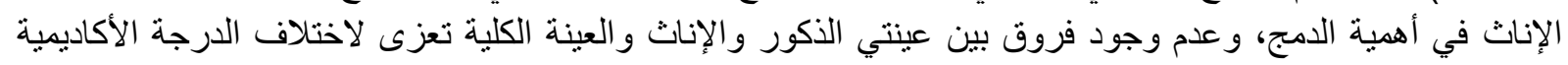

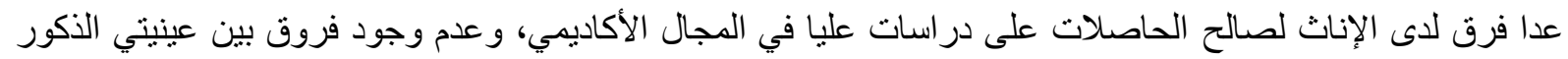

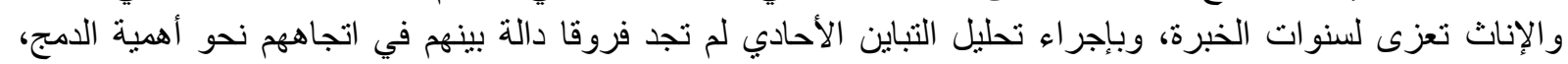

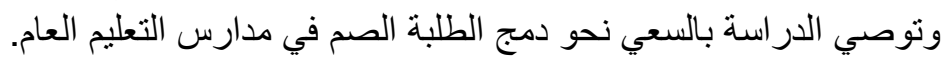

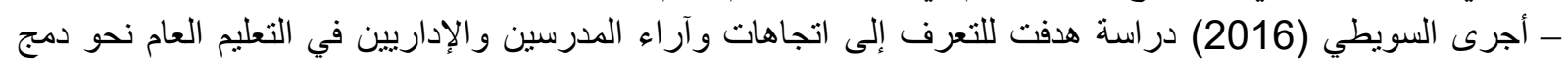

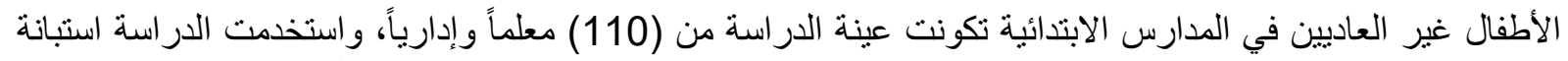

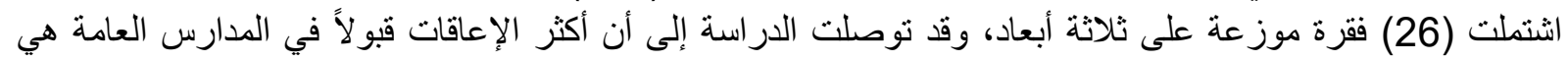

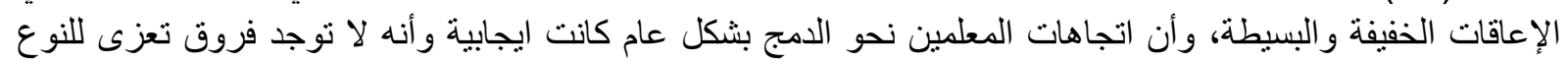

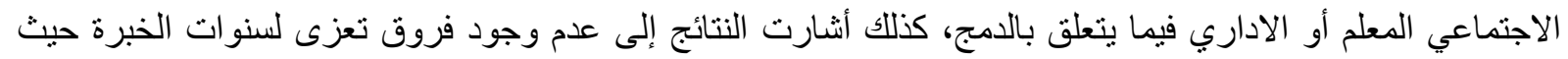

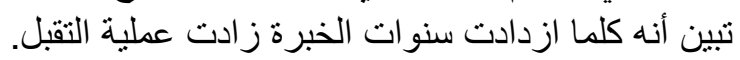

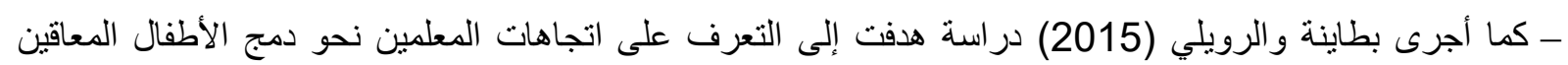

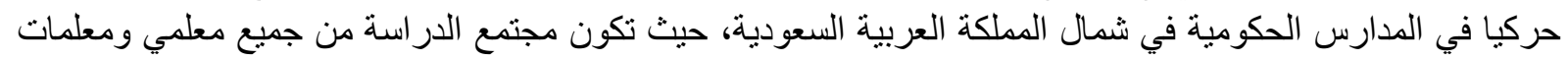

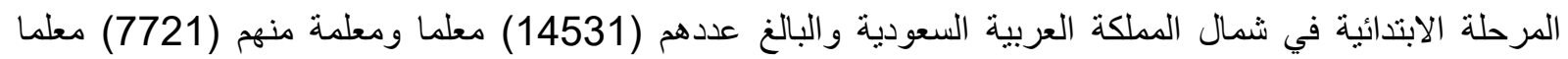

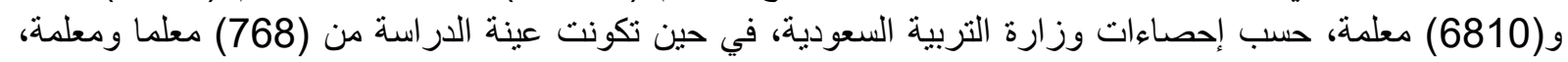

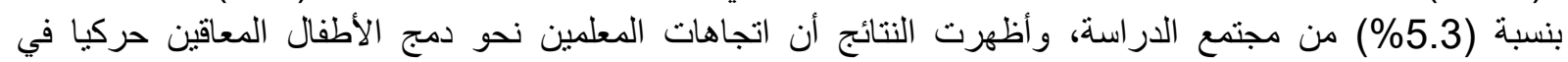
المدرسة العادية كانت إيجابية.

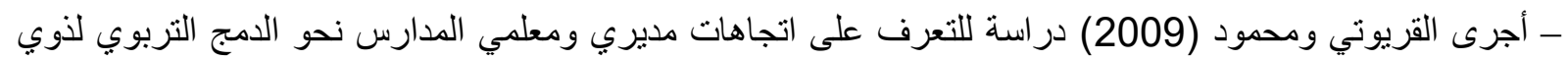

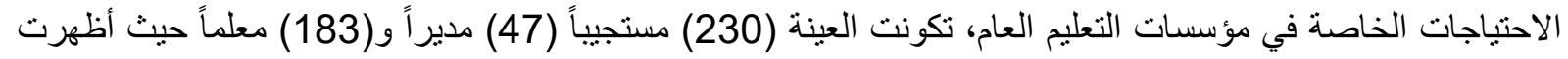

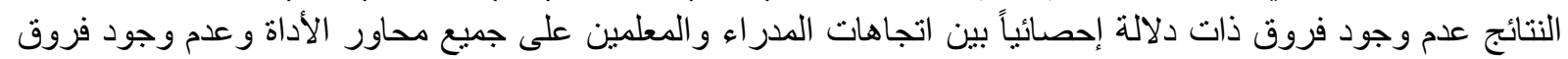

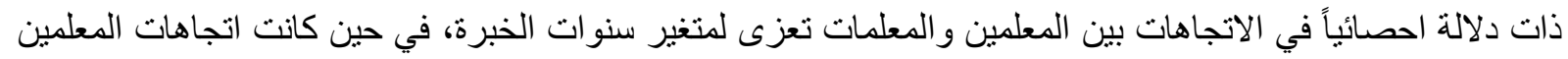

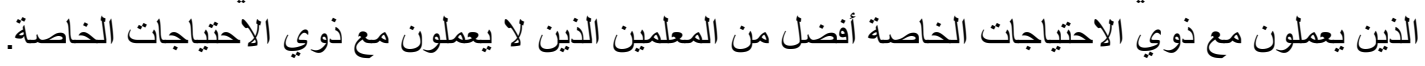

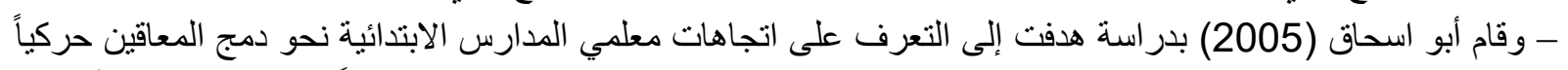

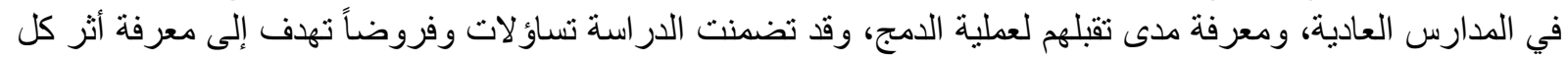

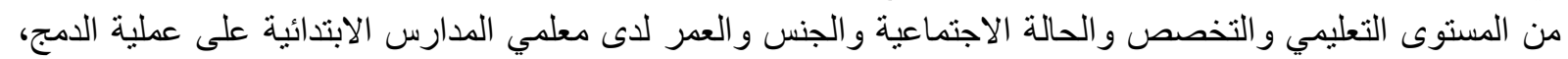

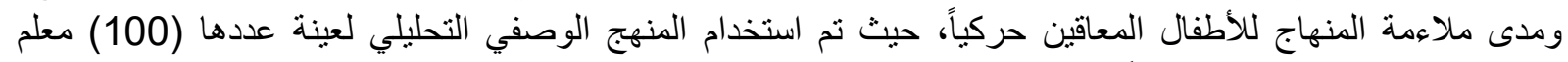

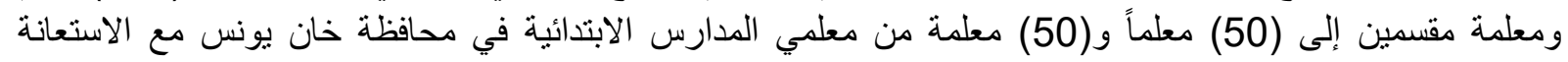

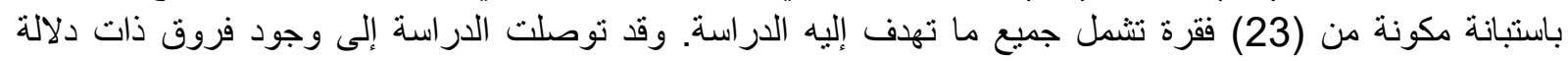

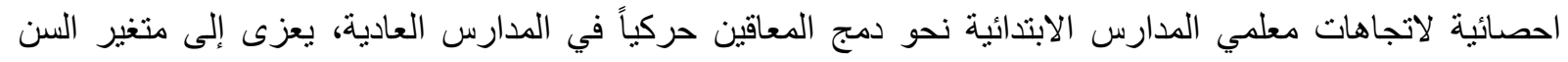

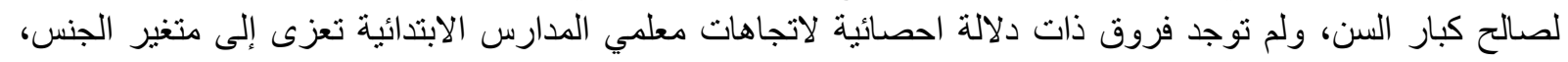

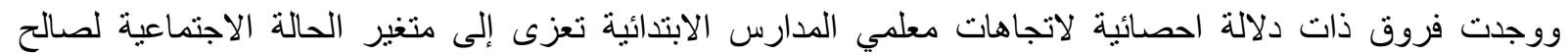

المنزوجين.

- و أجرى حبايب، و عبد الله (2005) دراسة هدفت للتعرف إلى اتجاهات مديري المدارس و المعلمين نحو دمج الطلبة

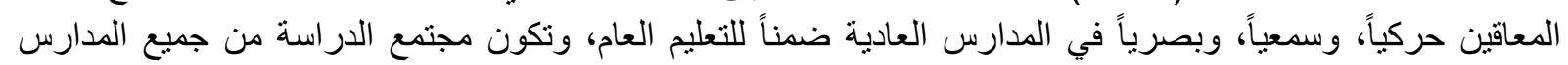

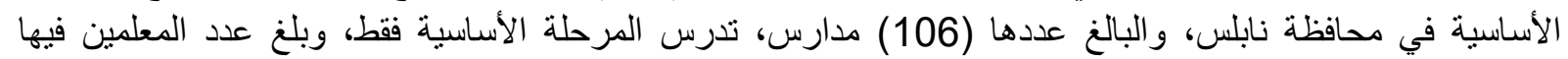

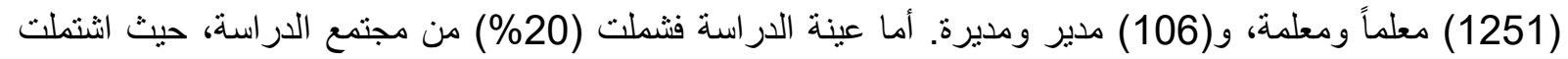

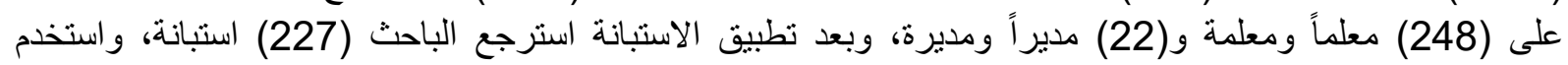

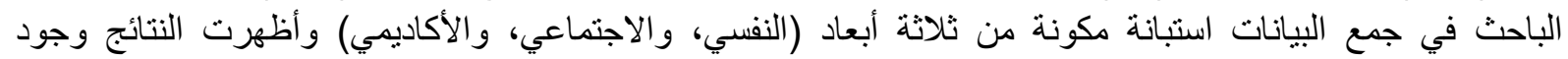
اتجاهات ايجابية نو عاً ما نحو دمج المعاقين حركياً، وسمعياً وبصرياً في التعليم العام، وجاءي، والاءت الإعاديا الإقة الحركية في المرتبة 
الأولى من حيث أولوية الدمج، ثم السمعية، ثم البصرية، كما أظهرت عدم وجود فروق في الاتجاهات نعزى لمتغير

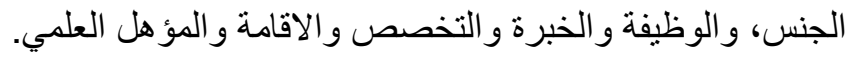

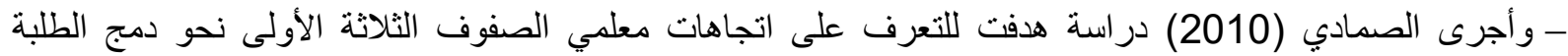

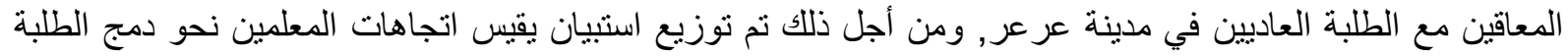

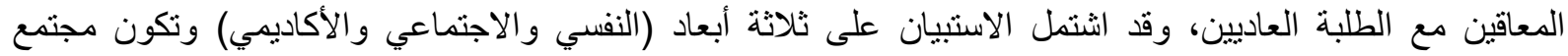

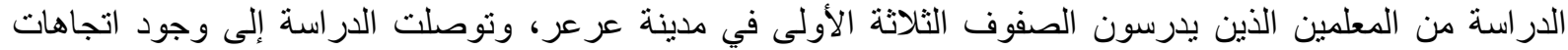

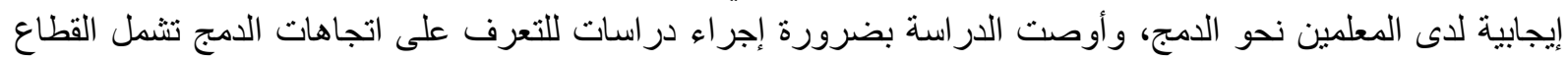

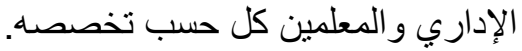

\section{الاراسات الأجنبية}

ـ دراسة بريزنر (Praisner, 2003) ركزت على اتجاهات مدراء المدارس الابندائية نحو الدمج التربوي و علاقتها ببعض المتغير ات كالتدريب والخبرة وتحديد المكان التربوي الملائم، و أظهرت النتائج أن واحداً من بين كل خمس الته مدراء التهاء

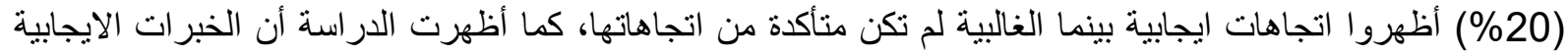

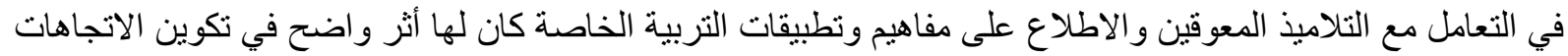

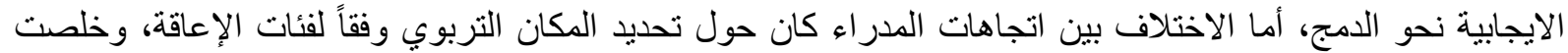

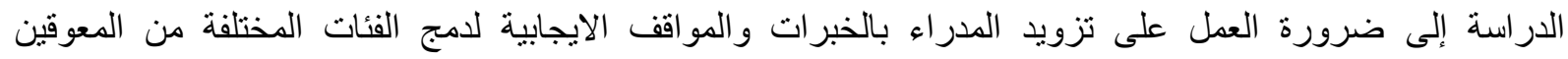
وتزويدهم بالتدريب اللازم.

- وسعت دراسة سازبوري ومكروجر (2002) Salisbury and McGregor إلى التعرف على المناخ الاداري

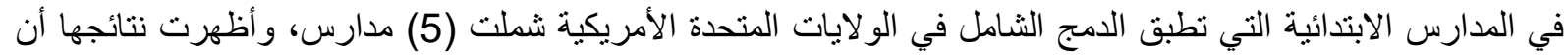

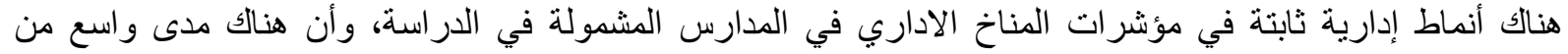

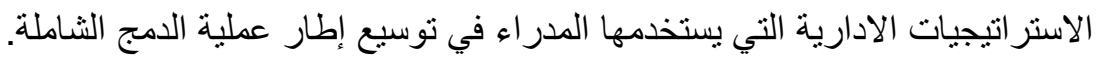

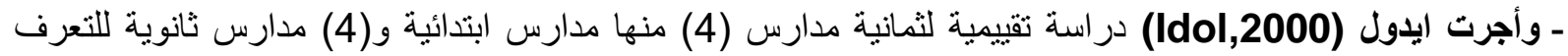

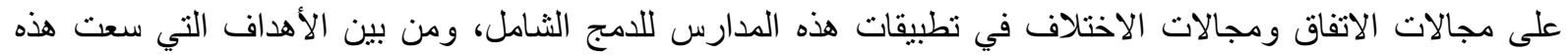

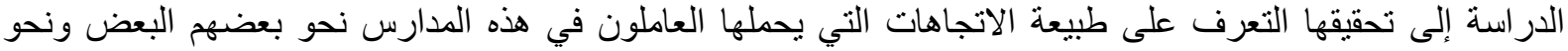

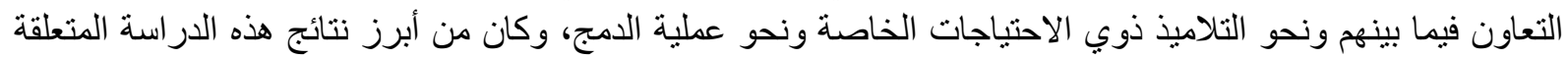

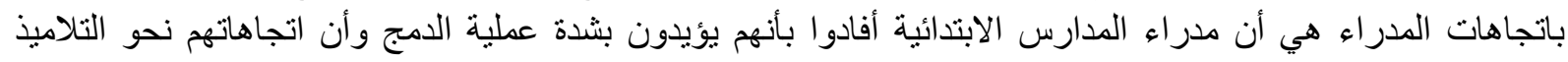

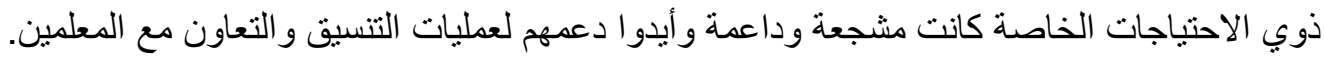

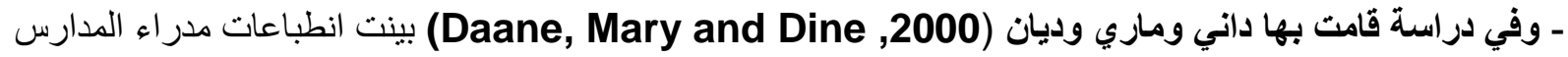

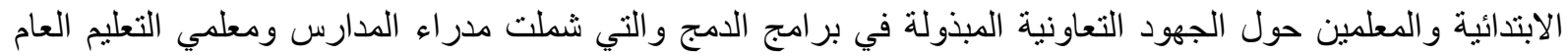

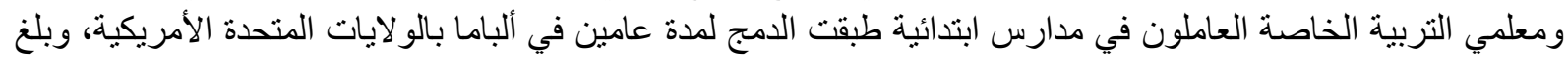

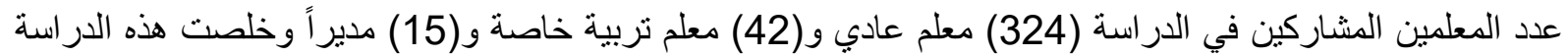

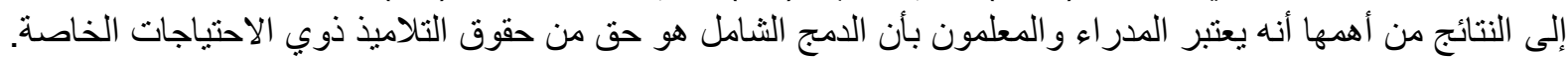

التعقيب على الاراسات السابقة: الت

تتشابه الدراسة الحالية مع بعض الدراسات كدراسة أجرى قطناني (2019) دراسة هدفت إلى الكثف عن اتجاهات

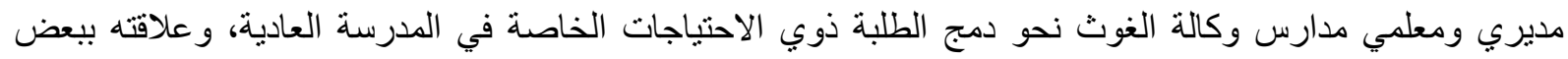

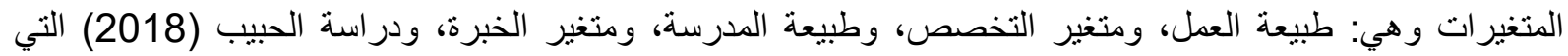

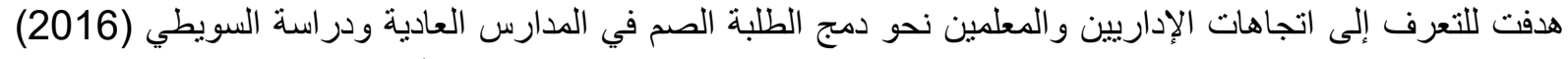

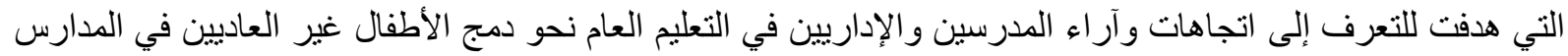

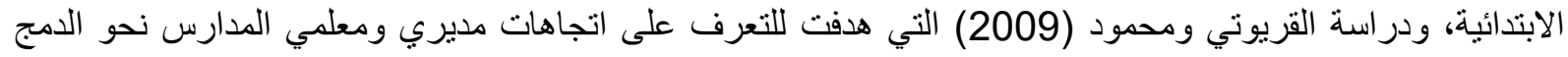

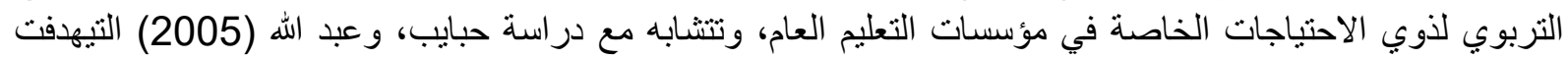

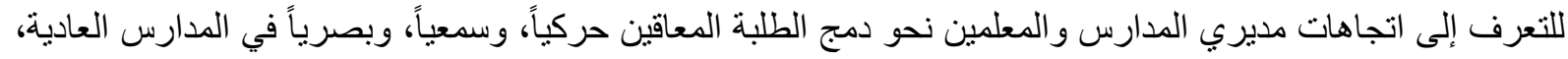


وتختلف عن الدراسة الدر اسات السابقة بكونها ركزت على قياساتجاهات مديري المدارس الحكومية نحو دمج الطلبة ذوي

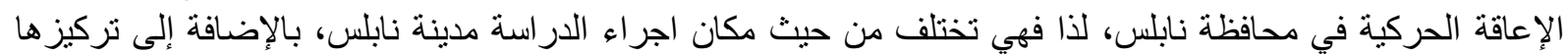

على فئة المعاقين حركياً.

الطريقة والإجراءات

منهجية الدراسة: تقوم هذه الدراسة على استخدام المنهج الوصفي المسحي، وقد استخدم هذا المنهج لملائمته لموضوع المانس الدراسة المتعلق بقياس اتجاهات مديري الددارس الحكومية نحو دمج الطلبة ذوي الإعاقة الحركية في محافظة نابلس. مجتمع الاراسة: تكون مجتمع الدراسة من جميع مديري المدارس في محافظة نابلس و البالغ عددهم (267) مدير ومديرة. عينة الاراسة: تم توزيع الاستبانة بطريقة عشوائية على عينة مكونة من (167) مدير ومديرة في محافظة نابلس،

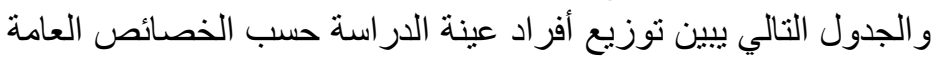
جدول رقم (1): توزيع أفر اد عينة الدر اسة حسب الخصائص العامة

\begin{tabular}{|c|c|c|c|}
\hline النسبة المئوية \% & العدد & فئات المتغير & المتغير \\
\hline 47.9 & 80 & ذكر & \multirow{2}{*}{ الجنس } \\
\hline 52.1 & 87 & انثى & \\
\hline 70.7 & 118 & يكالوريوس & \multirow{3}{*}{ المستوى التعليمي } \\
\hline 23.4 & 39 & ماجستير & \\
\hline 6.0 & 10 & دكتور اة & \\
\hline 12.6 & 21 & أقل من 5 سنوات & \multirow{3}{*}{ الخبرة } \\
\hline 45.5 & 76 & 10-5 سنو ات & \\
\hline 41.9 & 70 & 10 سنو ات فاكثر & \\
\hline
\end{tabular}

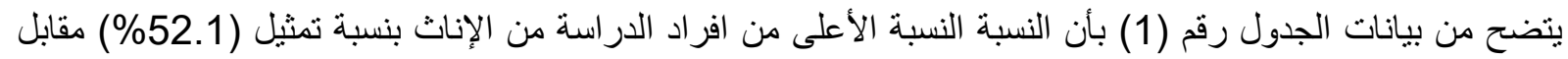

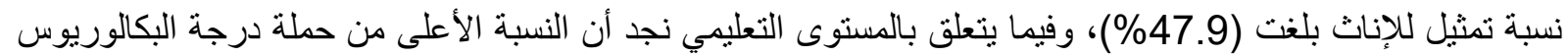

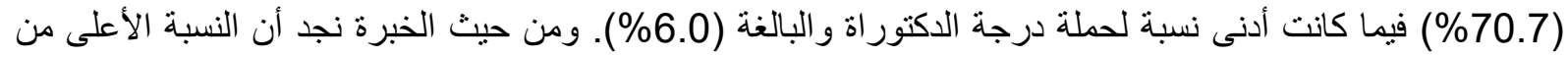

ذوي الخبرة 5-10 سنوات و البالغة (45.5\%) وانت أدنى نسبة تمثيل لذوي الخبرة أقل من 5 سنوات البالغة (12.6\%) (10).

أداة الاراسة:

تم تطوير أداة (مقياس) التربية الأخلاقية بالرجوع إلى الأدب النظري والدراسات السابقة قطناني (2019) (20019) الحبيب

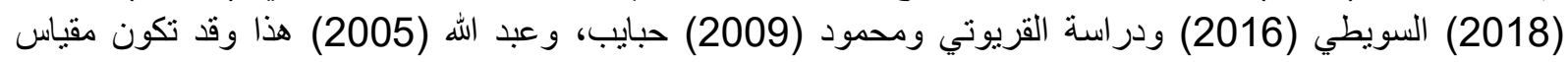

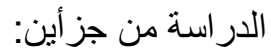

الجزء الاول: يتضمن المعلومات الديمغر افية، و المكونة من: (الجنس، المستوى التعليمي، الخبرة).

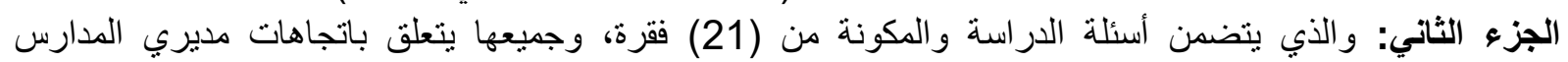

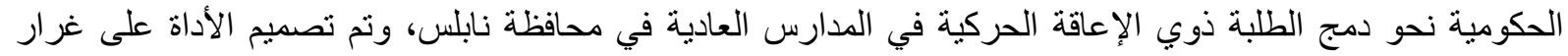


وقد صنفت إجابات فقر ات الاستبيان وفقا لمقياس ليكرت (Likert) الخماسي وحددت بخمس إجابات حسبت أوز انها رقمياً على النحو الآتي:

\begin{tabular}{|c|c|}
\hline 5 درجات & او افق بشدة \\
\hline 4 درجات & او افق \\
\hline 3 درجات & محايد \\
\hline 2 درجة & اعارض \\
\hline 1 درجة & اعار ض بشدة \\
\hline
\end{tabular}

ولتفسير المتوسطات الحسابية لتقديرات أفراد عينة الدراسة على كل فقرة من فقرات المقياس؛ تم استخدام المعيار

\begin{tabular}{|c|c|}
\hline درجة المو افقة & المتوسط الحسابي \\
\hline منخفضة & من 1.00 - أقل من 2.33 \\
\hline منوسطة & من 2.34 - أقل من 3.66 \\
\hline مرتفعة & من 3.67 - 5.00 \\
\hline
\end{tabular}

الإحصائي الآتي:

حيث تم حساب طول الفئة من خلال قسمة أكبر قدمة-أصغر قيمة =1-5 =1-33

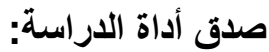

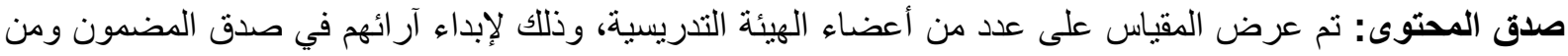

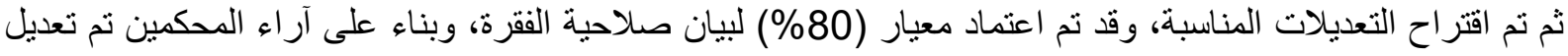

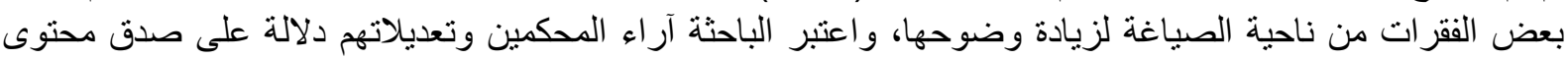
أداة الدراسة مما يشير للصدق الظاهري للأداة.

ثبات أداة الدراسة:

جرى استخراج معامل الثبات، طبقاً لكرونباخ ألفا (Cronbach Alpha) للاتساق الداخلي بصيغته النهائية الكلية، وبلغ الإنة قيمة معامل الثبات لكافة فقرات أداة الدراسة (الفات

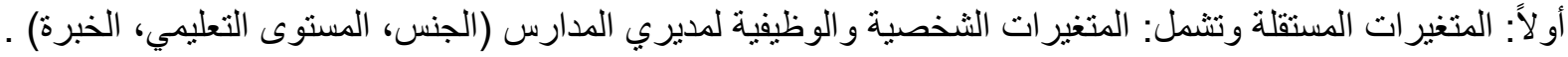

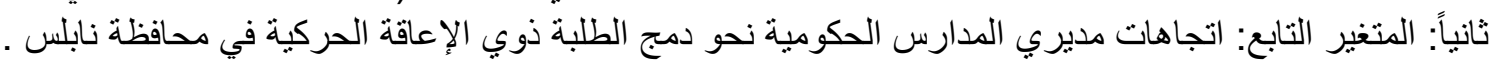

المعالجات الإحصائية المستخدمة:

Statistical SPSS) بغرض الإجابة على أسئلة الدراسة، واختبار صحة فرضياتها، تم استخدام الرزمة الإحصائية (Package For Social Sciences: التكرارات والنسب المئوية والمتوسطات الحسابية والانحر افات المعيارية، ولاحتبار الفروق في الاتجاهات نم استخدام اختبار (ت) للعينات المستقلة، وتحليل التباين الاحادي. واستخدم معامل الفا كرونباخ لاختبار ثبات اداة الدات الداسة. 
نتائج السؤال الاول: ما اتجاهات مدر اء المدارس الحكومية نحو دمج الطلاب ذوب الإعاقة الحركية في محافظة نابلس؟

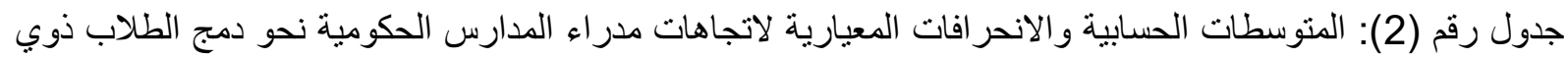

\begin{tabular}{|c|c|c|c|c|c|}
\hline دالمو افقة & 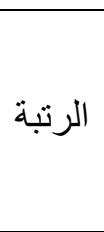 & في الانحر & 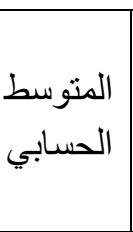 & 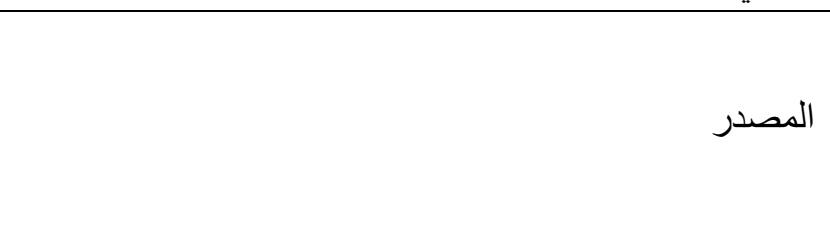 & 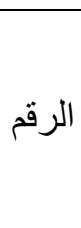 \\
\hline متوسط & 17 & 1.31 & 3.63 & تعديلات دمت ذلى البناء المدرسي والإعاقة الحركية في المدارس إلى إجراء & 1 \\
\hline 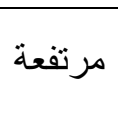 & 11 & 1.30 & 3.68 & وسائل دمساعدة ذنساعدهم على الإعاقة الحركية في المدارس بلى إلى توفر & 2 \\
\hline متوسط & 18 & 1.38 & 3.59 & الأسوتاج دمج ذضوي الإعاقة الحركية إلى توعية أقرانهم من & 3 \\
\hline 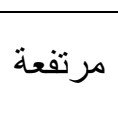 & 6 & 1.37 & 3.81 & أقرناهم الأسوياء. دي الإعاقة الحركية إلى تفهم اعاقتهم من قبل & 4 \\
\hline متوسط & 16 & 1.43 & 3.63 & طبيعة الطلبة ذوي الإعلية الدمج بحاجة إلى تهيئة بيئة مناسبة تتناسب مع & 5 \\
\hline متوسط & 20 & 1.40 & 3.56 & زيادة قدر أنهم التحصيلية. المعاقين حركياً في المدارس العادية سيؤدي إلى & 6 \\
\hline مرتفعة & 8 & 1.26 & 3.79 & أعارض بشدة دمج المعاقين حركياً في المدارس العادية. & 7 \\
\hline متوسط & 14 & 1.37 & 3.66 & دمج المعاقين حركياً سيؤثر سلباً على أداء المعلمين العاديين. & 8 \\
\hline 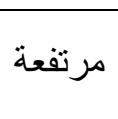 & 10 & 1.31 & 3.69 & 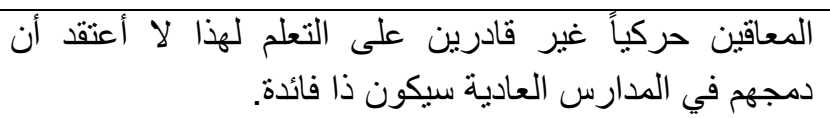 & 9 \\
\hline 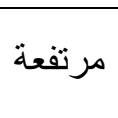 & 12 & 1.28 & 3.68 & تحسين اتجاهات المعلمين المعاقين حركياً في المدارس العادية سيؤدي إلى العاديين نحوهم. & 10 \\
\hline متوسط & 21 & 1.38 & 3.55 & على سلوك أن دمج الدعاء الطلبن حركياً في العداديين. & 11 \\
\hline 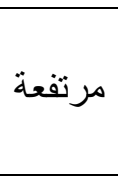 & 9 & 1.38 & 3.71 & 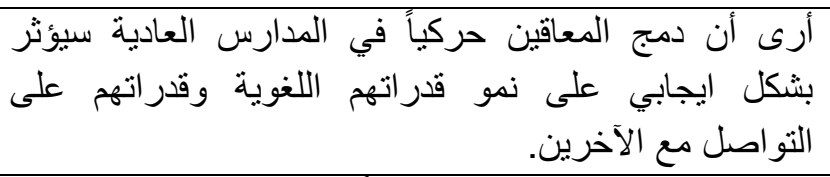 & 12 \\
\hline متوسط & 15 & 1.39 & 3.65 & أفضل دمج الطلبة المعاقين حركياً في صفوف خاصة ضمن & 13 \\
\hline مرتفعة & 2 & 1.26 & 3.98 & من حق الطلبة ذو الإعاقة الحركية الالتحاق بالمدارس العادية. & 14 \\
\hline 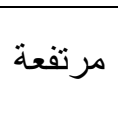 & 4 & 1.28 & 3.88 & ايجابية بينهم وبين الطلبة المعاقين حركيا سيؤدب إلى تكوين علاقات & 15 \\
\hline 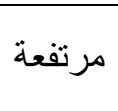 & 1 & 1.25 & 4.01 & أفضادية. ادماج الطلبة ذو الإعاقة الحركية بيناء ملحق بالمدرسة & 16 \\
\hline متوسط & 13 & 1.42 & 3.66 & معلومات وخبرة الطلبة المعاقين حركياً في المدارس العادية سيزيد من & 17 \\
\hline
\end{tabular}




\begin{tabular}{|c|c|c|c|c|c|}
\hline مرتفعة & 5 & 1.39 & 3.88 & بينهم وبين الطلبة العاديين. المعاقين حركياً سيؤدي إلى مشكلات سلوكية & 18 \\
\hline مرتفعة & 7 & 1.37 & 3.81 & أرىى أن الدافع نحو دمج الطلبة المعاقين حركياً في المدارس & 19 \\
\hline مرتفعة & 3 & 1.25 & 3.93 & إن زيادة بر امج الدمج جاء لقاء بفضل الحو افز المالية المقدمة & 20 \\
\hline متوسط & 19 & 1.49 & 3.57 & إن دمتيات وتجهيز الطلبة المعاقين حركياً في المدارس العبادية بحاجة إلى تعميمها على جميع المدارس. & 21 \\
\hline مرتفعة & --- & 1.00 & 3.88 & & \\
\hline
\end{tabular}

يلاحظ من بيانات الجدول رقم (2) وجود درجة مرتفعة من اتجاهات مدراء المدارس الحكومية نحو دمج الطلاب ذوبي

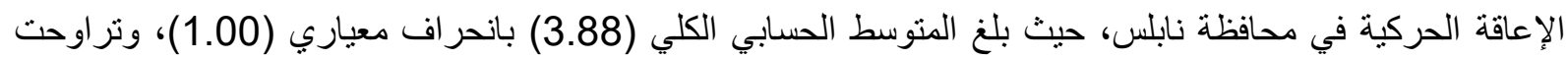

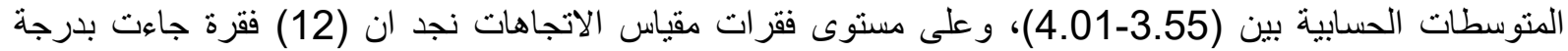

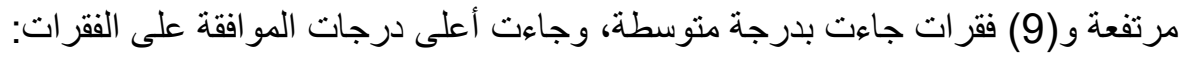

ـ في الترتيب الاولى جاءت الفقرة رقم (16) التي تنص على "أفضل ادماج الطلبة ذو الإعاقة الحركية بيناء ملحق بالمدرسة العادية" بمنوسط حسابي (3.98) وبانحر اف معياري (14.26 (1.26).

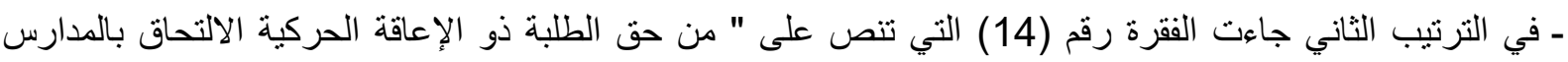
العادية" بمتوسط حسابي (4.01) وبانحر اف معياري (1.25) (14).

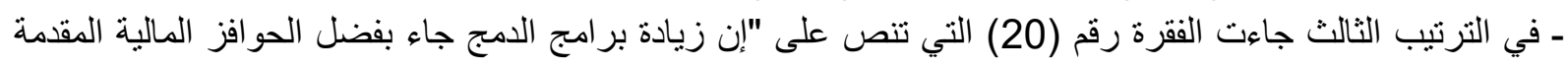
للمدر اء وليس لقناعتهم بجدو اها" بمنو سط حسابي (3.93) وبانحر اف معياري (1.25).

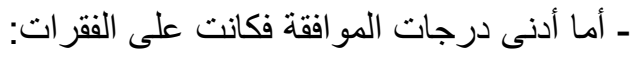

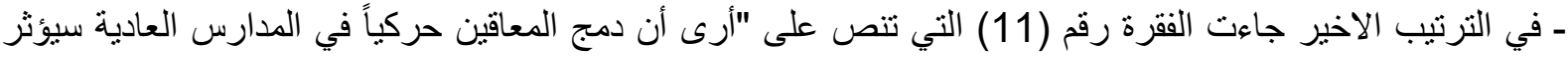

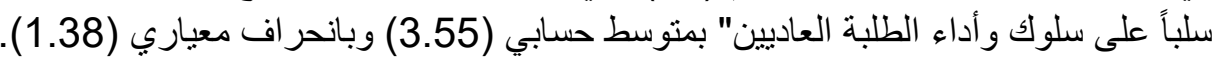

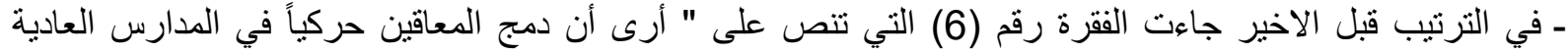

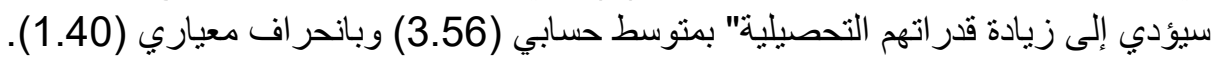

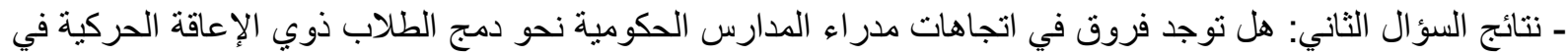
محافظة نابلس باختلاف المتغير ات (الجنس، المستوى التعليمي، الخبرة)؟

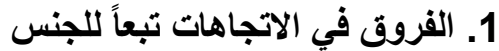
جدول رقم (3): المتوسطات الحسابية والانحر افات المعيارية لاتجاهات مدر اء المدارس الحكومية نحو دمج الطلاب ذوي

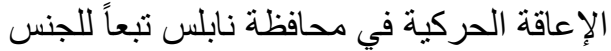

\begin{tabular}{|c|c|c|c|c|c|c|}
\hline الاحصائية & الحرية & قالمحسوبة (ت) & الانحرياري & الحسابي & العدد & الجنس \\
\hline \multirow{3}{*}{0.473} & \multirow{3}{*}{165} & \multirow{3}{*}{0.719} & 1.06 & 3.67 & 80 & ذكور \\
\hline & & & 0.93 & 3.78 & 87 & إناث \\
\hline & & & 1.00 & 3.73 & 167 & الكلي \\
\hline
\end{tabular}

تشير المتوسطات الحسابية إلى وجود فروق ظاهرية في اتجاهات مدراء المدارس الحكومية نحو دمج الطلاب ذوي

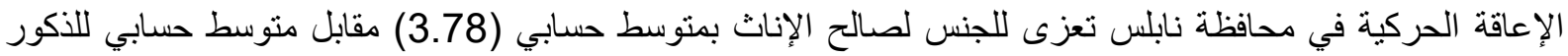

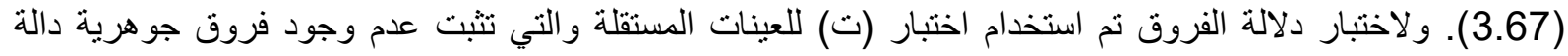

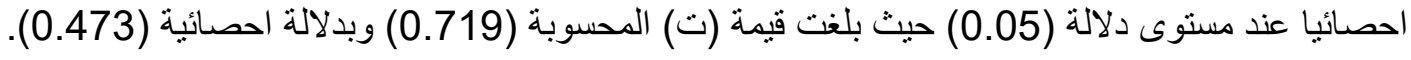


جدول رقم (4): المتوسطات الحسابية والانحر افات المعيارية لاتجاهات مدر اء المدارس الحكومية نحو دمج الطلاب ذوي الإعاقة الحركية في محافظة نابلس تبعاً لمستوى التعليمي الانحي

\begin{tabular}{|c|c|c|c|}
\hline الانحر اف المعياري & المتوسط الحسابي & 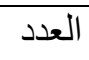 & مستوى التحصيل التعليمي \\
\hline 1.04 & 3.65 & 118 & بكالوريوس \\
\hline 0.77 & 3.96 & 39 & ماجستير \\
\hline 1.23 & 3.73 & 10 & دكتور اه \\
\hline 1.00 & 3.73 & 167 & الكلي \\
\hline
\end{tabular}

تشير المتوسطات الحسابية إلى وجود فروق ظاهرية في اتجاهات مدراء المدارس الحكومية نحو دمج الطلاب ذوي

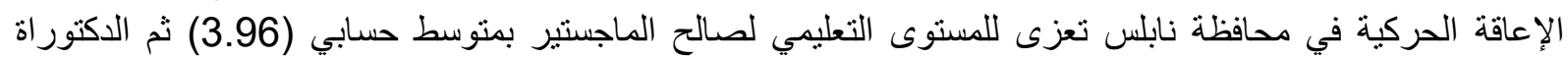

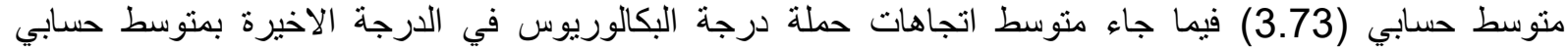
(3.65). و لاختبار دلالة الفروق في الاتجاهات بين المستويات التعليمية تم استخدام تحليل التباين الاحادي: جدول رقم (5): نتائج تحليل التباين الاحادي الاختبار دلالة الفروق في الاتجاهات بين المستويات التعليمية الثلاث

\begin{tabular}{|c|c|c|c|c|c|}
\hline الدلالة & قيمة & متوسط & درجات & مجموع & \multirow{2}{*}{ مصدر التباين } \\
\hline الإحصـائية & المحسوبة & المربعات & الحرية & المربعات & \\
\hline \multirow[t]{3}{*}{0.243} & 1.429 & 1.409 & 2 & 2.817 & بين المجمو عات \\
\hline & & 0.986 & 164 & 161.728 & داخل المجمو عات \\
\hline & & & 166 & 164.546 & الكلي \\
\hline
\end{tabular}

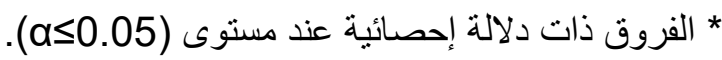

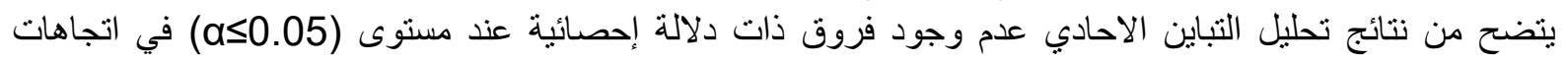

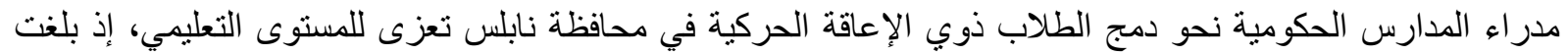
قيمة (ف) المحسوبة (1.429) و الدلالة الاحصائية لها (0.243).

\section{3. الفروق في الاتجاهات تبعاً للخبرة}

جدول رقم (6): المتوسطات الحسابية والانحر افات المعيارية لاتجاهات مدر اء المدارس الحكومية نحو دمج الطلاب ذوي الإعاقة الحركية في محافظة نابلس تبعاً للخبرة الانحرة

\begin{tabular}{|c|c|c|c|}
\hline الانحر اف المعياري & المتوسط الحسابي & العدد ال العد & الخبرة \\
\hline 0.99 & 4.15 & 21 & أقل من 5 سنو ات \\
\hline 1.01 & 3.67 & 76 & 10-5 سنوات \\
\hline 0.97 & 3.68 & 70 & 10 سنو ات فاكثر \\
\hline 1.00 & 3.73 & 167 & الكلي \\
\hline
\end{tabular}

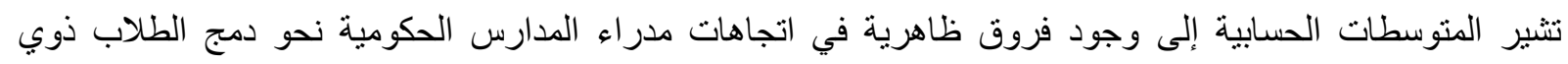

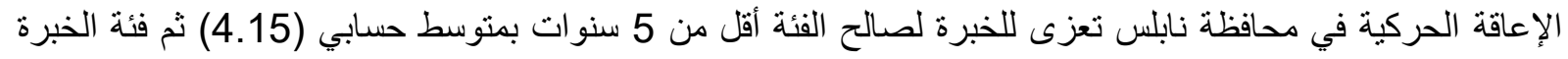

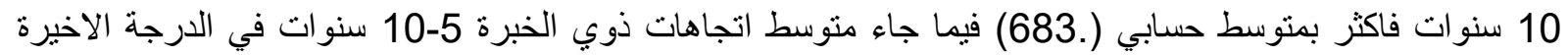

بمنوسط حسابي (3.67). و لاختبار دلالة الفروق في الاتجاهات بين فئات الخبرة تم استخدام تحليل التباين الاحادي:

جدول رقم (7): نتائج تحليل التباين الاحادي الاختبار دلالة الفروق في الاتجاهات بين فئات الخبرة الثلاث

\begin{tabular}{|c|c|c|c|c|c|}
\hline الإحصائية & قالمحسوبة (ف) & المربعات & الحرية & المربعات & مصدر التباين \\
\hline 0.126 & 2.101 & 2.055 & 2 & 4.110 & بين المجمو عات \\
\hline & & 0.978 & 164 & 160.436 & داخل المجمو عات \\
\hline & & & 166 & 164.546 & الكلي \\
\hline
\end{tabular}




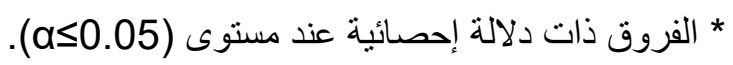

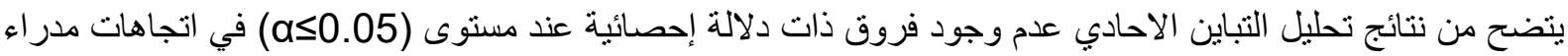

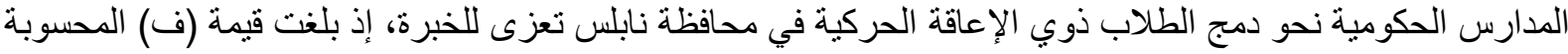

$$
\text { (1.422.101) والدالة الاحصائية لها (0.126). }
$$

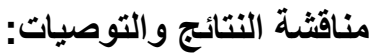

مناقتة النتائج المتعلقة بالسؤ ال الاول: ما اتجاهات مدراء المدارس الحكومية نحو دمج الطلاب ذوي الإعاقة الحركية في محافظة نابلس؟ بينت الدراسة وجود اتجاهات ايجابية مرتفعة لاى مدراء المدارس الحكومية نحو دمج الطلاب ذوي الإعاقة الحركية في

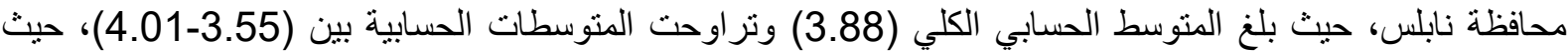

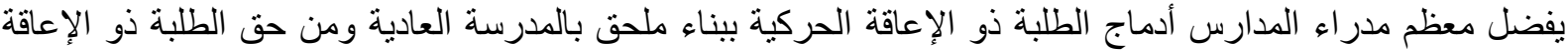

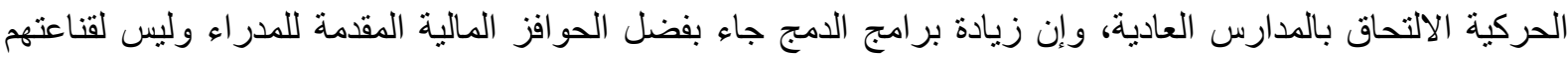

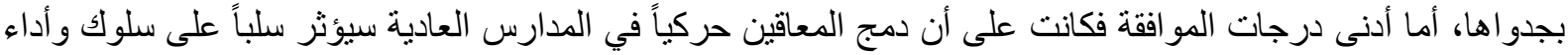

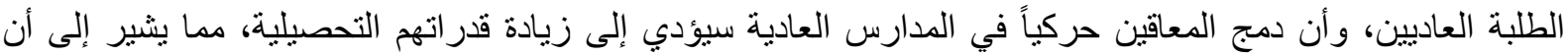

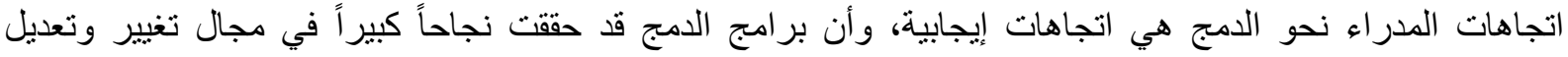

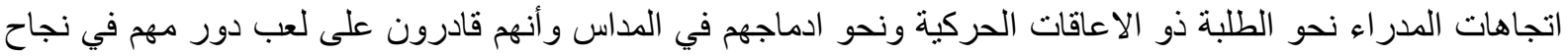
هذه البرامج وتتفق هذه النتيجة مع الغالبية العظمى من الدراسات السابقة، وهذا يتفق مع نتائج دراسة البطاينة والرائة الرويلي (2015) حيث أظهرت النتائج أن اتجاهات المعلمين نحو دمج الأطفال المعاقين حركيا في المدرسة العادية العادية كانت إيجابية

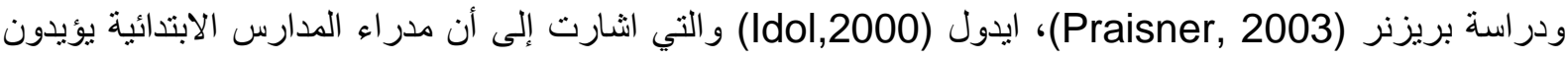

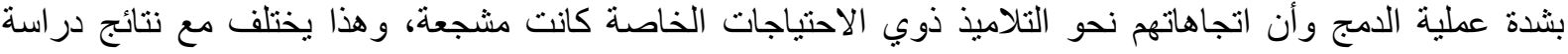

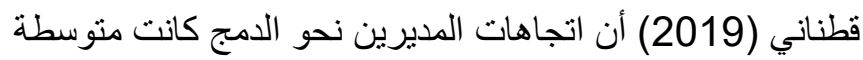

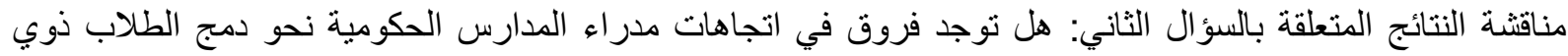

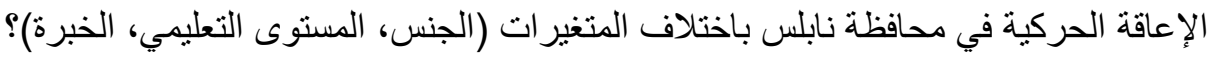

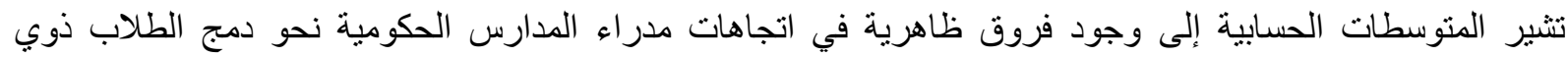

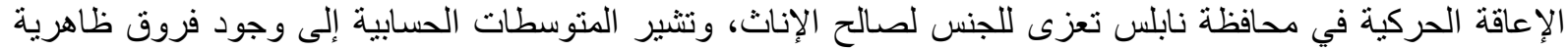

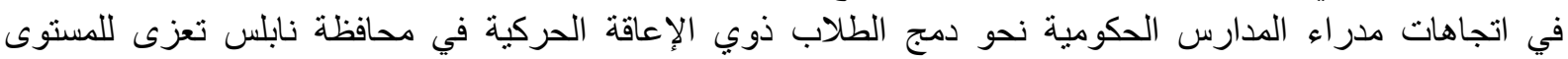

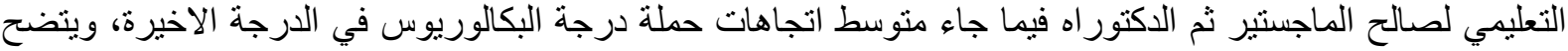

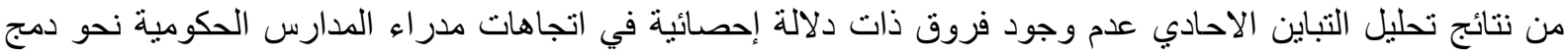

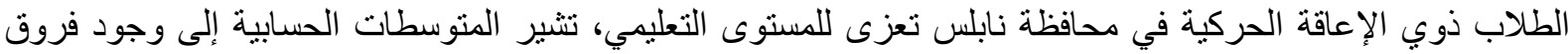

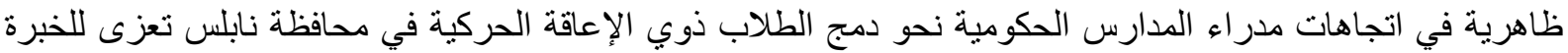

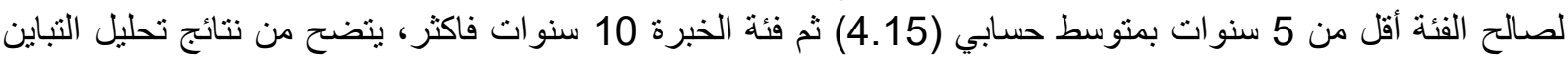

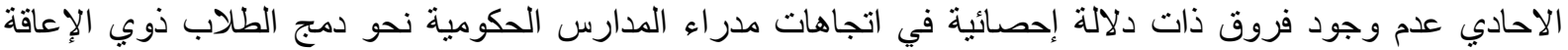

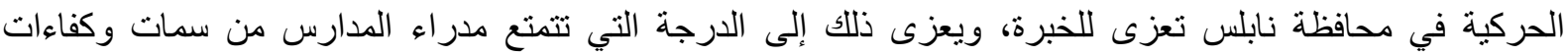

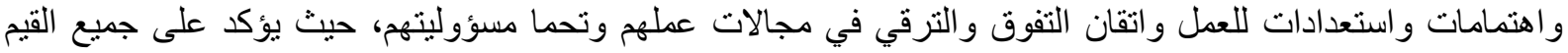

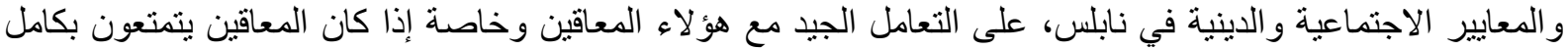

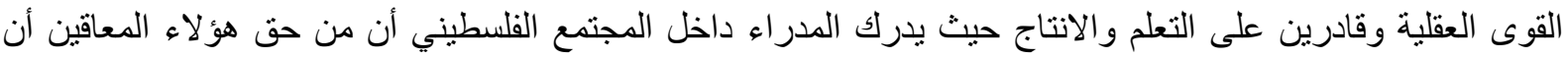

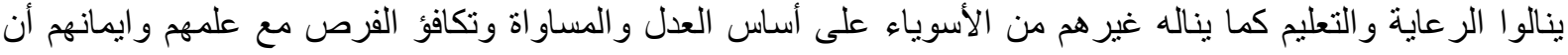

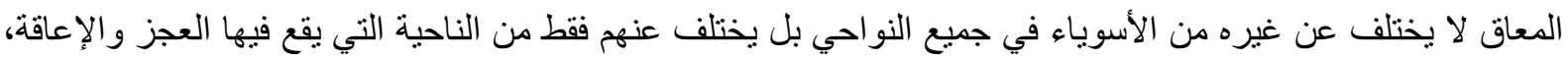

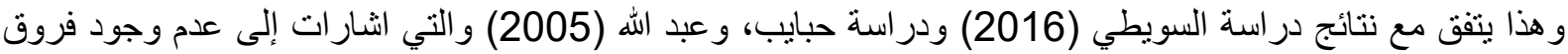
في الاتجاهات تعزى لمتغير الجنس، والوظيفة والخبرة والتخصص ور والاقامة و المؤهل العلمي. وعلي. 
بناء على نتائج الدر اسة فإنها توصي بما يلي:

- تهيئة المدارس بما يسهم في العمل على توعية جميع العاملين لقبول فكرة الادماج بصورة افضل ليتم نجاحها بالثكل

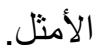

ـ تهيئة الأطفال العاديين ومساعدتهم على تكوين وبناء اتجاهاتهم تجاه الطفال غير العاديين.

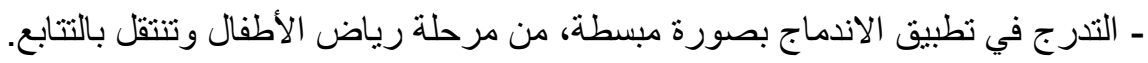

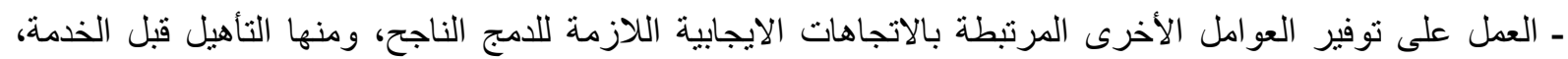

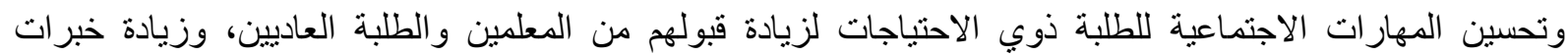

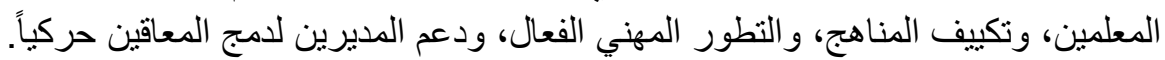

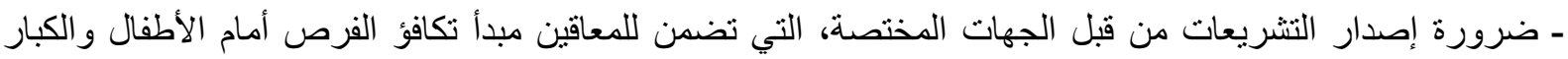

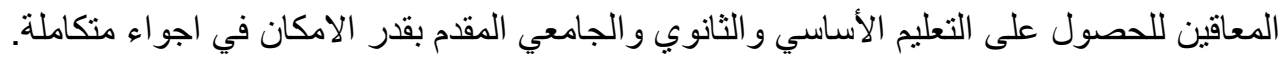
ـ ضرورة عقد الدورات وورشات العمل للمديرين في مجال دمج المعاقين و الأساليب الخاصة في في التعاء التعامل معهم.

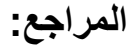

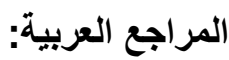

أبو اسحاق، سامي عوض (2005). اتجاهات معلمي المرحلة الابتدائية نحو دمج المعاق في المدارس العادية في محافظة

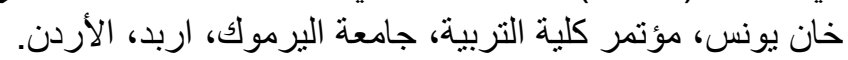

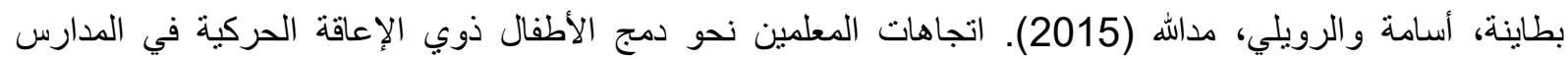

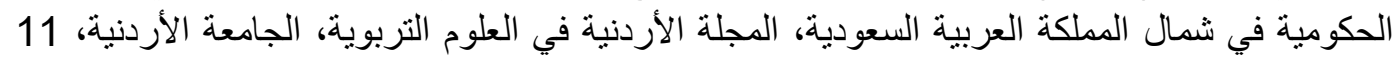

.168-145، 2015، (2)

الجهاز المركزي للإحصاء الفلسطيني (2019) بمناسبة اليوم العالمي للأشخاص ذوي الإعاقة، 2019/12/03

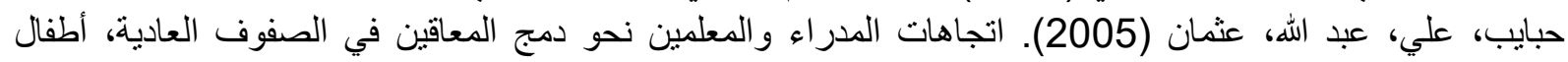

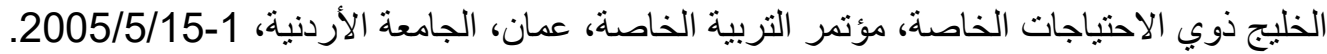

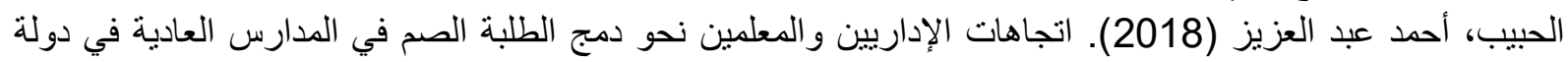

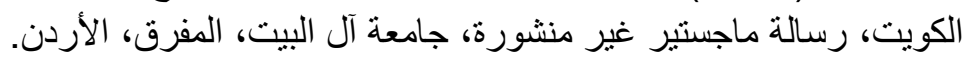

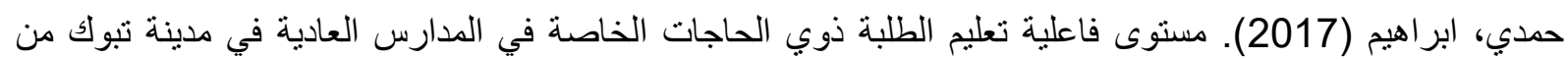

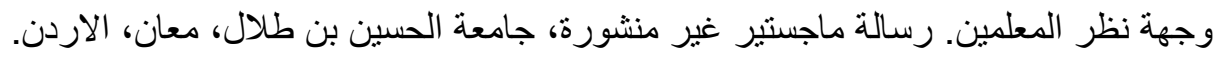

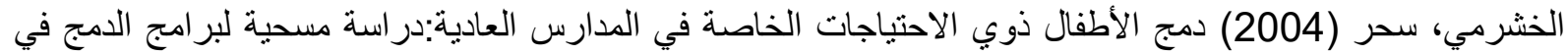

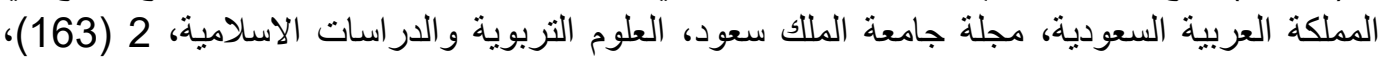

.842-793

الخطيب، جمال (2000). من هم المعوقون؟، مجلة الطفولة. 5 (32)، (32)، 12-263. الخطيب، جمال والحديدي، منى (2018). من مناهج واساليب تدريس في التربية الخاصة. ط(7)،

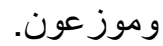

الروسان، فاروق (2000). سيكولوجية الأطفال غير العاديين. عمان: دار الفكر.

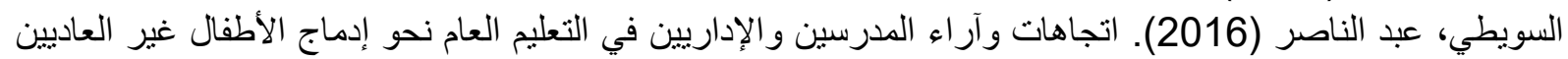

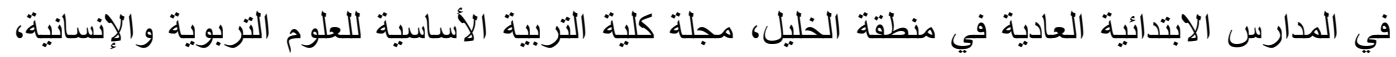

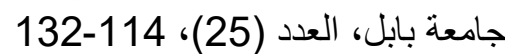

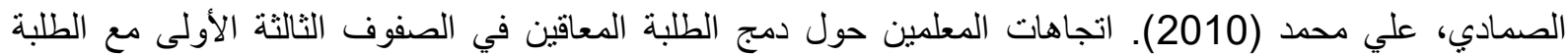

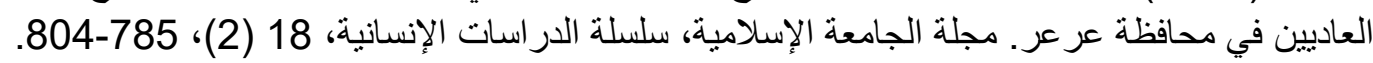

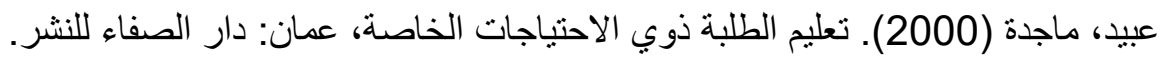

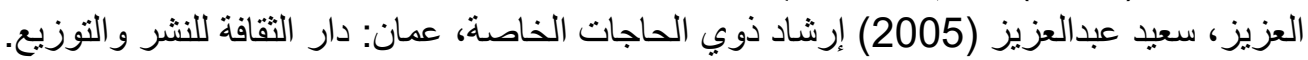


القريوتي، إبر اهيم، محمود، السيد (2009) اتجاهات المديرين و المعلمين نحو الدمج التربوي لذوي الاحتياجات الخاصة

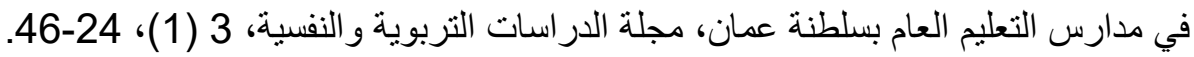

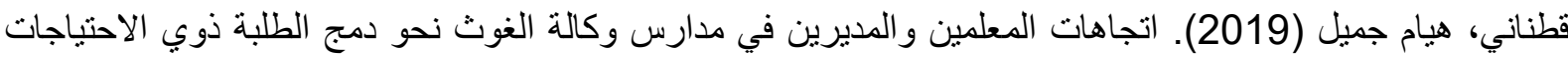

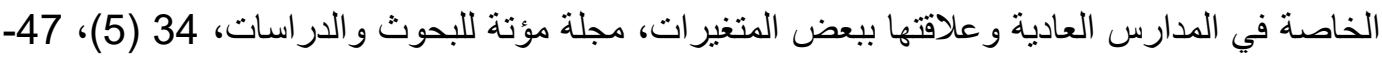

اللخاوي، محمد (2008). دور مديري الددارس الاعدادية بوكالة الغوث الدولية بمحافظات غزة في تنمية الإبداع

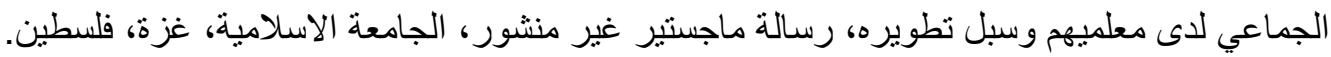
يحيى، خولة أحمد (2005) البر امج التربوية للأفر اد ذوي الحيره رساجة مات الخاصة، عمان: دار المسيرة.

Cassady, J. (2011). Teachers' attitudes toward the inclusion of students with autism and emotional behavioral disorder. Electronic Journal for Inclusive Education, 2 (7), 105-115.

Cindy, $L$ (2003). Attitudes of elementary schools principels towards the inclusion of students with disabilities, Council of Exceptional Children, 69 (2), 135-145.

Daane, C, Mary, B. and Dianne L (2000). Administratrators and Teachers Perceptions of the Collaborative Efforts of Inclusion in the Elementary Grades ,Education ,125,(2),338-441.

Futernick, K. (2007). A possible dream: Retaining California teachers so all students learn, Sacramento: California State University, 2 (10), 45-75.

Hipp,K. and Hoffman ,J.,(2000) How Leadership shared and vision emerge in the creation of learning communities,Paper presented at the 81st Annual Meeting of the American Educational Research Association, New Orleans,L.B.

Idol, L (2000) Toward Inclusion of Special Education Students in General Education, Remedial and Special Education, 27,(2),77-94.

Irvine, A., Lupart, J., Loreman, T., \& McGhie-Richmond, D. (2010). Educational leadership to create authentic inclusive schools: The experiences of principals in Canadian rural school district. Exceptionality Education International, 20 (2), 70- 88.

Praisner, C (2003). Attitudes of elementary school principals toward the inclusion of students with disabilities exceptional children, 69,(2), 135-145.

Rayan, T. (2009). Inclusive attitudes: a pre-service analysis. Journal of Research in Special Educational Needs, 9, 180-187.

Ross-Hill, R. (2009). Teacher attitude towards inclusion practices and special needs students. Journal of Research in Special Educational Needs, 9, 188-198.

Salisbury, C. And McGregor, G (2002) The Administrative Climate and Contexts of Inclusive elementary schools ,Exceptional Children,58 (2), 254-274.

Sims, S. (2015). General education teachers training to teach special needs students in the general education setting. Doctoral dissertation, Regent University.

Sze, S. (2006). A literature review: Pre-service teachers' attitudes toward students with disabilities. Education, 130, 53-56. 
Walker, T. (2012). Attitudes and Inclusion: An Examination of Teacher's Attitude towards Including students with disabilities, Dissertations. 401. http://ecommons.luc.edu/luc_diss/401 